Article

\title{
Biosynthesis of the Novel Endogenous 15-Lipoxygenase Metabolites N-13-Hydroxy-octodecadienoyl-ethanolamine and 13-Hydroxy-octodecadienoyl-glycerol by Human Neutrophils and Eosinophils
}

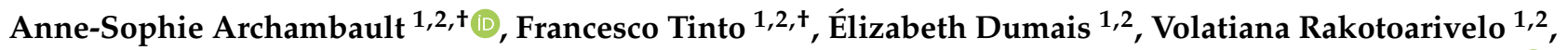 \\ Magdalena Kostrzewa ${ }^{3}$, Pier-Luc Plante ${ }^{4}$, Cyril Martin 1,2, Mélissa Simard 1,2,5, Cristoforo Silvestri 1,2 (D), \\ Roxane Pouliot $^{5}{ }^{\mathbb{D}}$, Michel Laviolette ${ }^{1}$, Louis-Philippe Boulet ${ }^{1}$, Rosa Maria Vitale ${ }^{3} \mathbb{D}$, Alessia Ligresti ${ }^{3}$ (D), \\ Vincenzo Di Marzo 1,2,3,4,6,7 and Nicolas Flamand 1,2,*(D)
}

1 Centre de Recherche de l'Institut Universitaire de Cardiologie et de Pneumologie de Québec, Faculté de Médecine, Université Laval, Québec City, QC G1V 4G5, Canada;

Anne-Sophie.archambault@criucpq.ulaval.ca (A.-S.A.); FrancescoTinto88@gmail.com (F.T.);

Elizabeth.Dumais@criucpq.ulaval.ca (É.D.); Volatiana.Rakotoarivelo@criucpq.ulaval.ca (V.R.); cyril.martin@criucpq.ulaval.ca (C.M.); Melissa.Simard@criucpq.ulaval.ca (M.S.);

Cristoforo.Silvestri@criucpq.ulaval.ca (C.S.); Michel.Laviolette@criucpq.ulaval.ca (M.L.);

check for

updates

Citation: Archambault, A.-S.; Tinto,

F.; Dumais, É.; Rakotoarivelo, V.;

Kostrzewa, M.; Plante, P.-L.; Martin,

C.; Simard, M.; Silvestri, C.; Pouliot,

R.; et al. Biosynthesis of the Novel

Endogenous 15-Lipoxygenase

Metabolites N-13-Hydroxy-

octodecadienoyl-ethanolamine and 13-Hydroxy-octodecadienoyl-glycerol

by Human Neutrophils and

Eosinophils. Cells 2021, 10, 2322.

https://doi.org/10.3390/cells10092322

Academic Editor: Fabrizio Vincenzi

Received: 6 August 2021

Accepted: 31 August 2021

Published: 5 September 2021

Publisher's Note: MDPI stays neutral with regard to jurisdictional claims in published maps and institutional affiliations.

Copyright: (c) 2021 by the authors. Licensee MDPI, Basel, Switzerland. This article is an open access article distributed under the terms and conditions of the Creative Commons Attribution (CC BY) license (https:// creativecommons.org/licenses/by/ $4.0 /)$. lpboulet@med.ulaval.ca (L.-P.B.); vincenzo.dimarzo@criucpq.ulaval.ca (V.D.)

2 Canada Excellence Research Chair on the Microbiome-Endocannabinoidome Axis in Metabolic Health (CERC-MEND), Université Laval, Québec City, QC G1V 0A6, Canada

3 Endocannabinoid Research Group, Institute of Biomolecular Chemistry, Consiglio Nazionale Delle Ricerche (CNR), 80078 Pozzuoli, Italy; m.kostrzewka@gmail.com (M.K.); rmvitale@icb.cnr.it (R.M.V.); aligresti@icb.cnr.it (A.L.)

4 Institut sur la Nutrition et les Aliments Fonctionnels, Centre NUTRISS, École de Nutrition, Faculté des Sciences de L'agriculture et de L'alimentation, Université Laval, Québec City, QC G1V 0A6, Canada; pier-luc.plante.1@ulaval.ca

5 Faculté de Pharmacie de l'Université Laval and Centre de Recherche en Organogénèse Expérimentale de l'Université Laval/LOEX, Axe Médecine Régénératrice, Centre de Recherche du CHU de Québec-Université Laval, Québec City, QC G1V 0A6, Canada; Roxane.Pouliot@pha.ulaval.ca

6 Joint International Unit between the Consiglio Nazionale delle Ricerche (CNR), 80078 Pozzuoli, Italy

7 Canada on Chemical and Biomolecular Research on the Microbiome and Its Impact on Metabolic Health and Nutrition (UMI-MicroMeNu), Université Laval, Québec City, QC G1V 0A6, Canada

* Correspondence: Nicolas.Flamand@criucpq.ulaval.ca; Tel.: +1-418-656-8711 (ext. 3733)

+ These authors equally contributed to this work.

Abstract: The endocannabinoids 2-arachidonoyl-glycerol and $N$-arachidonoyl-ethanolamine are lipids regulating many physiological processes, notably inflammation. Endocannabinoid hydrolysis inhibitors are now being investigated as potential anti-inflammatory agents. In addition to 2-arachidonoyl-glycerol and $\mathrm{N}$-arachidonoyl-ethanolamine, the endocannabinoidome also includes other monoacylglycerols and $\mathrm{N}$-acyl-ethanolamines such as 1-linoleoyl-glycerol (1-LG) and $N$-linoleoyl-ethanolamine (LEA). By increasing monoacylglycerols and/or $N$-acyl-ethanolamine levels, endocannabinoid hydrolysis inhibitors will likely increase the levels of their metabolites. Herein, we investigated whether 1-LG and LEA were substrates for the 15-lipoxygenase pathway, given that both possess a 1Z,4Z-pentadiene motif, near their omega end. We thus assessed how human eosinophils and neutrophils biosynthesized the 15-lipoxygenase metabolites of 1-LG and LEA. Linoleic acid (LA), a well-documented substrate of 15-lipoxygenases, was used as positive control. $\mathrm{N}$ 13-hydroxy-octodecadienoyl-ethanolamine (13-HODE-EA) and 13-hydroxy-octodecadienoyl-glycerol (13-HODE-G), the 15-lipoxygenase metabolites of LEA and 1-LG, were synthesized using Novozym 435 and soybean lipoxygenase. Eosinophils, which express the 15-lipoxygenase-1, metabolized LA, 1-LG, and LEA into their 13-hydroxy derivatives. This was almost complete after five minutes. Substrate preference of eosinophils was LA > LEA > 1-LG in presence of 13-HODE-G hydrolysis inhibition with methyl-arachidonoyl-fluorophosphonate. Human neutrophils also metabolized LA, 1-LG, and LEA into their 13-hydroxy derivatives. This was maximal after 15-30 s. Substrate preference was LA $\gg 1-L G>$ LEA. Importantly, 13-HODE-G was found in humans and mouse tissue 
samples. In conclusion, our data show that human eosinophils and neutrophils metabolize 1-LG and LEA into the novel endogenous 15-lipoxygenase metabolites 13-HODE-G and 13-HODE-EA. The full biological importance of 13-HODE-G and 13-HODE-EA remains to be explored.

Keywords: endocannabinoid; linoleic acid; linoleoyl-glycerol; 13-HODE; 2-arachidonoyl-glycerol; anandamide; eicosanoid; eosinophils; neutrophils; $N$-linoleoyl-ethanolamine

\section{Introduction}

The endocannabinoids 2-arachidonoyl-glycerol (2-AG) and $N$-arachidonoyl-ethanolamine (AEA) are bioactive lipids mediating their effects mostly by activating the cannabinoid receptors $C_{1}$ and $C_{2}$. As such, they modulate several physiological responses, the most recognized ones being nociception, appetite, adipogenesis, and inflammation [1,2]. The levels of 2-AG and AEA are tightly regulated. As such, 2-AG is hydrolyzed into arachidonic acid (AA) by at least six lipases, notably the MAG lipase [3-8], while AEA is hydrolyzed into AA by the fatty acid amide hydrolases (FAAH)- 1 and -2 and the $N$ acylethanolamine acid amidase (NAAA) [9-11]. Once hydrolyzed into AA, notably by leukocytes, 2-AG can be further metabolized into eicosanoids such as prostaglandins and leukotrienes [12-14]. Apart from being hydrolyzed into AA, 2-AG and AEA can also be directly metabolized by eicosanoid biosynthetic enzymes, the most documented metabolites being the cyclooxygenase-2-derived prostaglandins-glycerols (PG-G) and prostamides, respectively [15], as well as by CYP450 enzymes [16]. The 12- and the 15-lipoxygenase (LO) pathways were also shown to metabolize AEA and 2-AG into their 12-hydroxy and 15-hydroxy derivatives [17-20].

The 15-LO pathway is particularly relevant when investigating 2-AG, AEA, and their congeners from the monoacylglycerol and $N$-acyl-ethanolamine families. Indeed, human 15-LO-1 and 15-LO-2 metabolize numerous unsaturated fatty acids possessing a 1Z,4Zpentadiene motif [20] and recent data indicate that additional $N$-acyl-ethanolamines are also metabolized by human 15-LOs. Indeed, LEA is notably metabolized into N-13-hydroxyoctoceaenoyl-ethanolamine (13-HODE-EA) by human recombinant 15-LO-1 and -2 [21], while $N$-docosahexaenoyl-ethanolamine (DHEA) is metabolized into 17-hydroxy-DHEA, 4,17-dihydroxy-DHEA, and 10,17-dihydroxy-DHEA by human neutrophils [22].

Human eosinophils and neutrophils express 15-LOs, eosinophils mainly expressing the 15-LO-1, and neutrophils mainly expressing the 15-LO-2 and/or possibly another LO [20]. As such, both leukocyte types biosynthesize 13(S)-hydroxy-octodecadienoic acid (13-HODE) from linoleic acid (LA) $[20,23,24]$. Moreover, human recombinant 15-LO-1 and 15-LO-2 can biosynthesize 13-HODE-EA from $N$-linoleoyl-ethanolamine (LEA) [21]. We thus postulated that 1-linoleoyl-glycerol (1-LG) would be metabolized into 13-hydroxyoctodecadienoyl-glycerol (13-HODE-G) and that eosinophils and neutrophils would biosynthesize 13-HODE-G and 13-HODE-EA in response to 1-LG and LEA, respectively. The chemical structures of 13-HODE, 13-HODE-G, and 13-HODE-EA are shown in Figure 1.
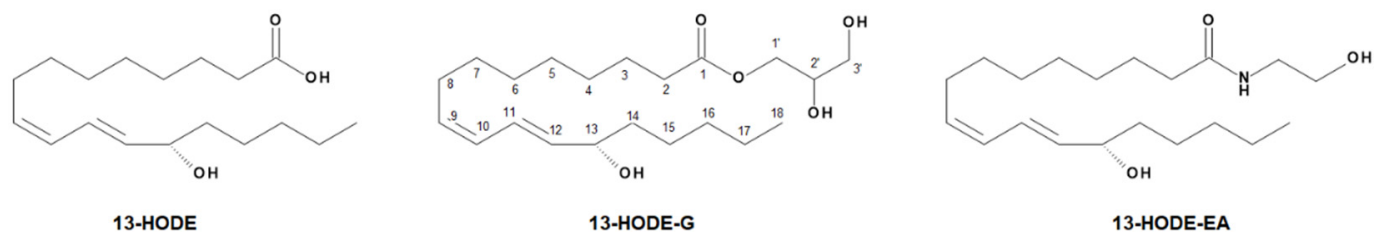

Figure 1. Chemical structures of 13-HODE, 13-HODE-G, and 13-HODE-EA.

Herein, we show that (1) the synthesis of 13-HODE-G was obtained from 1-LG using a strategy similar to what we recently reported for 13-HODE-EA [21]; (2) human recombinant 15-LO-1 and -2 biosynthesized 13-HODE-G and 13-HODE-EA from 1-LG and LEA, respec- 
tively; (3) human eosinophils and neutrophils metabolize 1-LG and LEA into 13-HODE-G and 13-HODE-EA, respectively; (4) serine hydrolase inhibition with MAFP is required to evaluate the ability of leukocytes to biosynthesize 13-HODE-G and (5) 13-HODE-G can be detected in several human and mouse tissues but, is unable to activate the same receptors as $1-\mathrm{LG}$.

\section{Materials and Methods}

\subsection{Materials}

DMSO, Dextran, LC-MS grade $\mathrm{MeOH}$, acetic acid, $\mathrm{MeCN}$, water, and chloroform were purchased from Thermo Fisher Scientific (Ottawa, ON, Canada). HPLC water was purified with a Milli-Q system (Millipore, Oakville, ON, Canada). Lymphocyte separation medium was from Corning (Corning, NY, USA) and HBSS from Wisent Bioproducts (St-Bruno, QC, Canada). Methyl-arachidonoyl-fluorophosphonate (MAFP), linoleic acid, linoleoylglycerol, and linoleoyl-ethanolamine were purchased from Cayman Chemicals (Ann Arbor, MI, USA). Soybean lipoxygenase Type I-B, deuterated solvents, and all the reagents used for synthesis were purchased from Sigma Aldrich (Oakville, ON, Canada) unless otherwise specified and used without further purification. Anti-CD16 conjugated with MicroBeads and MACS columns were purchased from Miltenyi Biotec (Auburn, CA, USA).

\subsection{Synthesis and Purification of $1-L G-d_{5}$}

For the synthesis of 1-LG- $\mathrm{d}_{5}$, we followed a previously documented strategy involving the enzyme Novozym 435 [25]. In brief, LA and glycerol- $\mathrm{d}_{5}$ ( 0.2 and $0.6 \mathrm{mmol}$, respectively) were dissolved in tert-butanol $(1.2 \mathrm{~mL})$. Then, molecular sieves and Novozym 435 (24 mg, $40 \% w / w)$ were added to the mixture. The reaction was initiated by placing the mixture in a thermoconstant orbital shaker (New Brunswick Scientific ${ }^{\mathrm{TM}}$, Edison, NJ, USA) and shook at $200 \mathrm{rpm}\left(5 \mathrm{~h}, 60^{\circ} \mathrm{C}\right)$. This led to the synthesis of $0.18 \mathrm{mmol}$ of $1-\mathrm{LG}-\mathrm{d}_{5}$. After cooling at room temperature, removal of the solvents was performed under reduced pressure. Purification of 1-LG- $\mathrm{d}_{5}$ was achieved by silica gel chromatography using $\mathrm{CHCl}_{3}-\mathrm{MeOH}$ $(98: 2, v / v)$.

\subsection{Synthesis and Purification of $13-H O D E-G$ and $13-H O D E-G-d_{5}$}

Our strategy to synthesize 13-HOGE-G (and 13-HODE-G-d $_{5}$ ) was elaborated based on the fact that soybean lipoxygenase can transform $N$-linoleoyl-ethanolamine (LEA) into 13-HODE-EA [26], a process we could repeat [21]. In brief, $0.01 \mathrm{mmol}$ of 1-LG or 1-LG-d was diluted in $100 \mathrm{~mL}$ of $\mathrm{Na}_{2} \mathrm{~B}_{4} \mathrm{O}_{7}(50 \mathrm{mM}, \mathrm{pH}$ 12). The reaction was initiated by adding $20 \mathrm{mg}$ of soybean lipoxygenase $(0.2 \mathrm{mg} / 1 \mathrm{~mL})$ and stirred for $15 \mathrm{~min}$ at room temperature. The hydroperoxides were then reduced by adding $2 \mathrm{~mL}$ of a freshly prepared sodium borohydride solution ( $1 \mathrm{M}$ in ethanol). The solution was acidified by the dropwise addition of glacial acetic acid ( $500 \mu \mathrm{L}$ over $1 \mathrm{~min}$ ) and gently stirred $15 \mathrm{~min}$ until foaming stopped. The resulting reaction products were then extracted with $300 \mathrm{~mL} \mathrm{CHCl}_{3}$, dried by adding $\mathrm{Na}_{2} \mathrm{SO}_{4}$, filtered, and concentrated in vacuo. The resulting residue was filtered over glass wool and purified by RP-HPLC as previously described [21] and showed retention time of $9.0 \mathrm{~min}$. The solvent was evaporated under vacuum and the purified product was weighted.

\subsection{Characterization with $1 D$ and $2 D N M R$}

All products and synthetic intermediate structures were assigned using ${ }^{1} \mathrm{H},{ }^{13} \mathrm{C}$, COSY, HSQC NMR spectra, and were recorded in $5 \mathrm{~mm}$ tubes on an Agilent $500 \mathrm{MHz}$ DD2 system (Agilent NMR System, Santa Clara, CA, USA) with a OneNMR probe. ${ }^{1} \mathrm{H}$ NMR and ${ }^{13} \mathrm{C}$ NMR chemical shifts are referenced to residual protons in deuterated solvents. Multiplicities are reported as singlet (s), doublet (d), triplet (t), quintet (q), multiplet (m), broad (br), or overlapping (ov). Chemical shifts are reported in ppm. Coupling constants are reported in $\mathrm{Hz}$. Protons were assigned using integrated ${ }^{1} \mathrm{H}-\mathrm{NMR}$ and $2 \mathrm{D}{ }^{1} \mathrm{H},{ }^{1} \mathrm{H}-$ gCOSY spectra to detect correlation between neighboring protons. The quaternary carbon 
was determined using the $1 \mathrm{D}^{13} \mathrm{C}$ experiments. Protons were then assigned to carbons using $2 \mathrm{D}^{1} \mathrm{H},{ }^{13} \mathrm{C}-\mathrm{HSQC}$ spectra showing single through-bond relationships and $\mathrm{CH}$ were discriminated from $\mathrm{CH}_{2}$ and $\mathrm{CH}_{3}$ with crosspeaks of different colors.

\subsection{Characterization with HR-ESI-MS/MS Spectrometry}

High-resolution mass spectrometry was performed on a Thermo Orbitrap Fusion tribrid mass spectrometer (Thermo Scientific, Bremen, Germany) using a Chemyx F100T2 syringe pump (Chemyx Inc., Stafford, TX, USA) running at $5 \mathrm{uL} / \mathrm{min}$. The mass spectrometer was operated in positive or negative ionization modes using the orbitrap detector at a resolution of 60,000. For CID, the collisional energy was set between 0 and $50 \mathrm{eV}$.

\subsection{Enzymatic Assays}

Recombinant human 15-LO-1 and 15-LO-2 enzymes were added to HEPES $25 \mathrm{mM}$ $+0.01 \%$ Triton $(14 \mu \mathrm{g} / \mathrm{mL}$ for $15-\mathrm{LO}-1,56 \mu \mathrm{g} / \mathrm{mL}$ for $15-\mathrm{LO}-2)$. A total of $10 \mu \mathrm{M}$ of the fatty acids were added to the buffer for $5 \mathrm{~min}$ (15-LO-1) or $15 \mathrm{~min}(15-\mathrm{LO}-2)$, at $37^{\circ} \mathrm{C}$. The final volume of the reaction mix was $100 \mu \mathrm{L}$. After the incubation, $50 \mu \mathrm{L}$ of $\mathrm{NaBH}_{4} 1 \mathrm{M}$ was added to the reaction, for $5 \mathrm{~min}$ at $37^{\circ} \mathrm{C}$. The reactions were stopped by adding $0.5 \mathrm{~mL}$ of cold $\left(-20^{\circ} \mathrm{C}\right)$ methanol $+0.01 \%$ acetic acid and kept at $-30{ }^{\circ} \mathrm{C}$ until further processing.

\subsection{Analysis of 13-HODE-G and 13-HODE-EA by LC-MS/MS}

For tissues samples, $10 \mathrm{mg}$ of tissue was put in $500 \mu \mathrm{L}$ of Tris Buffer, crushed with a pestle, mixed with $500 \mu \mathrm{L}$ of cold $\left(-20^{\circ} \mathrm{C}\right) \mathrm{MeOH}$ containing the internal standards, centrifuged at $10,000 \times g$ and the supernatant collected. All Samples were processed by adjusting the final volume to $1 \mathrm{~mL}$ (incubation buffer-MeOH mixture, 1/1, $v / v$ plus the internal standards). Samples $(1 \mathrm{~mL})$ were acidified with $0.575 \%$ of acetic acid and mixed with $1 \mathrm{~mL} \mathrm{CHCl} 3$. Samples were then vortexed for $1 \mathrm{~min}$, then centrifuged at $3000 \times g$ for $5 \mathrm{~min}$. The organic phase (lower phase) was harvested, dried under a stream of nitrogen and reconstituted with $25 \mu \mathrm{L}$ of solvent $\mathrm{A}\left(\mathrm{H}_{2} \mathrm{O}\right.$ containing $1 \mathrm{mM}$ of ammonium hydroxide and $0.05 \%$ of acetic acid) and $25 \mu \mathrm{L}$ of solvent $\mathrm{B}\left(\mathrm{MeCN} / \mathrm{H}_{2} \mathrm{O}, 95 / 5, v / v\right.$ containing $1 \mathrm{mM}$ of ammonium hydroxide and $0.05 \%$ of acetic acid). A total of $40 \mu \mathrm{L}$ of the samples were injected onto an HPLC column (Kinetex C8, $150 \times 2.1 \mathrm{~mm}, 2.6 \mu \mathrm{m}$, Phenomenex, Torrance, CA, USA) and eluted at a flow rate of $0.4 \mathrm{~mL} /$ minute using a discontinuous gradient as described previously [27]. The HPLC system was interfaced with the electrospray source of a Shimadzu 8050 triple quadrupole mass spectrometer and mass spectrometric analysis was done in the negative or positive ion mode using multiple reaction monitoring for the specific mass transition of the metabolites (Table 1). 15-LO metabolites were quantified using calibration curves, as described before [20].

Table 1. LC-MS quantification of 15-LO metabolites.

\begin{tabular}{ccccc}
\hline Lipid & Internal Standard Used & Q1 $\rightarrow$ Q3 & Retention Time (Min) & LLOQ (Fmol) \\
\hline 13-HODE-d & - & $299.10 \rightarrow 198.15$ & 9.89 & - \\
13-HODE-G-d & - & $358.00 \rightarrow 261.30$ & 8.76 & - \\
13-HODE-EA-d & - & $326.30 \rightarrow 66.20$ & 7.72 & - \\
13-HODE & 13-HODE-d & $295.5 \rightarrow 277.30$ & 9.94 & 25 \\
13-HODE-G & 13-HODE-G-d & $353.20 \rightarrow 261.2$ & 8.80 & 25 \\
13-HODE-EA & 13-HODE-EA-d $_{4}$ & $322.00 \rightarrow 62.2$ & 7.76 & 25 \\
\hline
\end{tabular}

\subsection{Isolation of Human Neutrophils and Eosinophils}

Neutrophils and eosinophils were isolated from the peripheral blood of healthy volunteers as described before [28]. First, platelet-rich plasma was discarded by centrifugation and erythrocytes were sedimented using HBSS containing $6 \%$ of dextran. Then, granulocytes were separated from mononuclear cells using a discontinuous gradient with the Lymphocyte separation medium. Residual erythrocytes were removed by hypotonic lysis with sterile water. Eosinophils and neutrophils were separated using magnetic bead 
conjugated anti-CD16 and MACS column, according to the manufacturer's instructions. Purity and viability were $>95 \%$ and were assessed by Diff-Quick coloration and Trypan blue exclusion, respectively.

\subsection{Cell Stimulations}

Prewarmed $\left(37^{\circ} \mathrm{C}\right)$ suspensions of human neutrophils $\left(5 \times 10^{6}\right.$ cells $\left./ \mathrm{mL}\right)$ or eosinophils $\left(10^{6}\right.$ cells $\left./ \mathrm{mL}\right)$ in HBSS containing $1.6 \mathrm{mM} \mathrm{CaCl}_{2}$ were incubated with $1 \mu \mathrm{M}$ MAFP for 5 min before the addition of LA, 1-LG, or LEA for different times or concentrations (see legends of Figures 3-8). Adenosine deaminase $(0.3 \mathrm{U} / \mathrm{mL})$ was added to neutrophil suspensions $10 \mathrm{~min}$ before the addition of the stimuli in order to remove the inhibitory constraint that adenosine has on their numerous responses [29]. Incubations were stopped by adding one volume of cold $\left(-20^{\circ} \mathrm{C}\right) \mathrm{MeOH}$ containing the internal standards (Table 1). Samples were then kept at $-30^{\circ} \mathrm{C}$ until further processing. Lipids were extracted and quantified by LC-MS/MS as described above.

\subsection{0. $C B_{1}$ and $C B_{2}$ Binding Assays} in [21].

The analysis of $\mathrm{CB}_{1}$ and $\mathrm{CB}_{2}$ receptor binding was performed exactly as described

\subsection{Analysis of PPAR- $\alpha, P P A R-\gamma$ and TRPV1 Functional Activity}

These assays we preformed exactly as described in [21].

\subsection{Computational Analysis of PPAR- $\alpha$ Binding}

13-HODE was retrieved from Pubchem (CID: 5282947). 13-HODE was then fully optimized using the GAMESS program [30] at the Hartree-Fock level with the STO-3G basis set and subjected to HF/6-31G*/STO-3G single-point calculations to derive the partial atomic charges using the RESP procedure [31]. Docking studies were performed with AutoDock v4.2 [32] by using the PPAR- $\alpha$ crystallographic structure (PDB ID: 2P54). Protein and ligands were processed with AutoDock Tools (ADT) package version 1.5.6rc1 [32] to merge non-polar hydrogens and calculate Gasteiger charges. Grids for docking evaluation with a spacing of $0.375 \AA$ and $60 \times 60 \times 60$ points, centered on the ligand binding site, were generated using the program AutoGrid v4.2 included in Auto-dock v4.2 distribution. A total of 100 molecular docking runs for each docking calculation were performed adopting a Lamarckian Genetic Algorithm (LGA) and the protocol already published [33]. Flexibility was used for all rotatable bonds of the docked ligands. For each docking run, the representative poses were selected on the basis of best binding energy values and visual inspection and underwent energy minimization with Amber16 package [34] using ff14SB version of AMBER ff14SB force field for the protein and gaff parameters for the ligand. To perform molecular dynamics simulations in solvent, the complexes were confined in TIP3P water periodic truncated octahedron boxes exhibiting a minimum distance between solute atoms and box surfaces of $10 \AA$, using the leap module of the AmberTools16 package. Molecular dynamics simulations were performed using a protocol published elsewhere [33]. Production runs were carried out for $100 \mathrm{~ns}$. The cpptraj module of AmberTools16 and program UCSF Chimera v1.10.1 were used to perform molecular dynamics analysis and to draw the figures, respectively.

\subsection{Ethics Committee Approval}

This study was approved by the local ethics committee (Comite d'éthique de la recherche de l'Institut universitaire de cardiologie et de pneumologie de Québec-Université Laval) and all participants signed an informed consent form. 


\section{Results}

\subsection{Synthesis of 1-LG- $d_{5}, 13-H O D E-G$, and 13-HODE- $d_{5}$}

We recently developed a strategy to synthesize 13-HODE-EA and 13-HODE-EA$\mathrm{d}_{4}$ from LEA and LEA- $\mathrm{d}_{4}$, respectively [21]. We basically applied a similar strategy to synthesize 1-LG- $\mathrm{d}_{5}, 13-\mathrm{HODE}-\mathrm{G}-\mathrm{d}_{5}$, and 13-HODE-G (Figure S1). First, we synthesized 1LG- $\mathrm{d}_{5}$ with Novozyme 435 , given that this compound was not commercially available. This reaction was very efficient ( $\sim 90 \%$ yield), and we confirmed the molecular structure of the latter using ${ }^{1} \mathrm{H}$ and ${ }^{13} \mathrm{C}$ NMR (Figures S2 and S3). We next performed the lipoxygenation of 1-LG and 1-LG- $\mathrm{d}_{5}$ using soybean lipoxygenase (Figure S1). The yield of this reaction was 30 and $40 \%$ for $13-$ HODE-G and 13-HODE- $\mathrm{d}_{5}$, respectively. 13-HODE-G (and 13-HODE- $\mathrm{d}_{5}$ ) was easily separated from 13-HODE by RP-HPLC and led to increased UV absorbance at $235 \mathrm{~nm}$, indicating the formation of a conjugated diene. (Figure 2A). Of note, the elution peak of 13-HODE-G consisted of a mixture of the $s n-2$ and -1(3) isomers.
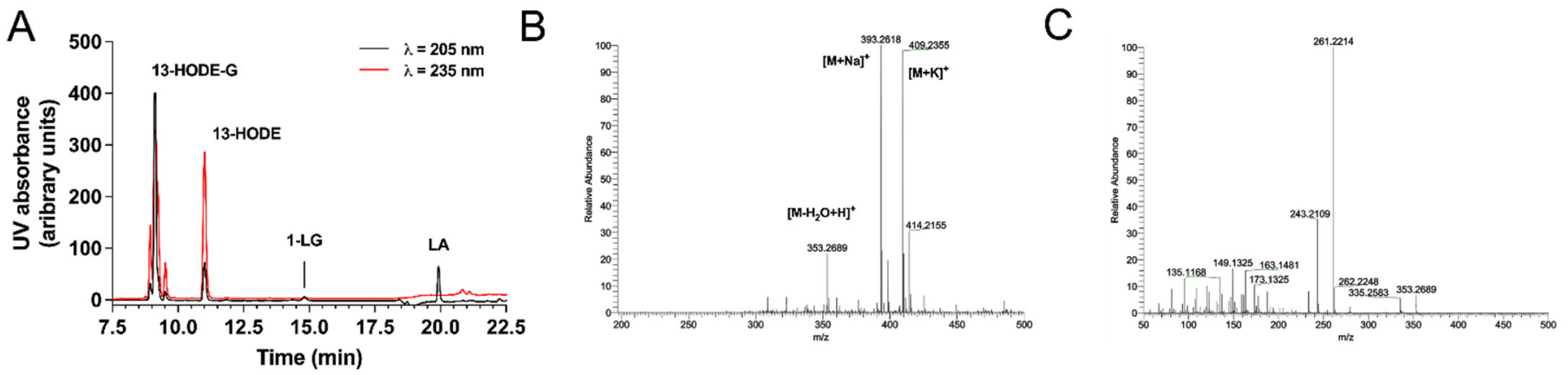

Figure 2. RP-HPLC chromatogram and mass spectrometry analysis of 13-HODE-G. (A) Separation of 13-HODE-G from other possible contaminants. The reaction products $(\sim 350 \mu \mathrm{g})$ of 1-LG with soybean lipoxygenase were loaded onto the HPLC column and eluted as described in Material and Methods. (B) Positive electrospray ionization mass spectrometry (ESI+) of 13-HODE-G. Positive electrospray ionization mass spectrometry (ESI+) of 13-HODE-G yielded three main cations; $\left[\mathrm{M}-\mathrm{H}_{2} \mathrm{O}+\mathrm{H}\right]^{+}$was found at $m / z$ 353.2689, $[\mathrm{M}+\mathrm{Na}]^{+}$at $m / z 393.2618$ and $[\mathrm{M}+\mathrm{K}]^{+}$at $m / z$ 409.2355. (C) Collision-Induced Dissociation (CID) at Higher-energy collisional dissociation (HCD) of $20 \mathrm{eV}$ of 13-HODE-G. CID of [M- $\left.\mathrm{H}_{2} \mathrm{O}+\mathrm{H}\right]^{+}$at $m / z$ 353.2689 led to the dominant product ion of $m / z 261.2214$.

The structure of the conjugated diene of 13-HODE-G and 13-HODE-G- $\mathrm{d}_{5}$ were confirmed by NMR as cis-trans on the basis of the coupling constants at positions 9-12. Indeed, the value of $\mathrm{J}_{9-10}$ was $11.0 \mathrm{~Hz}$, indicating the presence of a cis configuration double bond, whereas the coupling constant of $\mathrm{J}_{11-12}$ was $15.2 \mathrm{~Hz}$, characteristic of trans geometry (Table 2, Figures S4, S5, S8 and S9).

In contrast to 1-LG- $\mathrm{d}_{5}$, for which the signal of $\mathrm{H} 13$ was visible, the same signal in the ${ }^{1} \mathrm{H}-\mathrm{NMR}$ spectra of 13-HODE-G was completely overlapped by the 2'-CH2 signal of the glycerol. Therefore, HSQC and COSY experiments were set up to elucidate the presence of the hydroxyl group bound to the C13. The HSQC data showed a direct correlation $\mathrm{C} 13-\mathrm{H} 13(\delta \mathrm{H} 4.16 \mathrm{ppm}, \delta \mathrm{C} 72.9 \mathrm{ppm})$ and the value of the $\delta \mathrm{C}$ was typical of a carbon directly linked to hydroxyl group for the lipoxygenase metabolites (Figures S6 and S10). The COSY data showed crosspicks between H13-H14 ( $\delta \mathrm{H}-13$ 4.20, $\delta \mathrm{H}-14$ 1.25) and H13-H12 $(\delta \mathrm{H}-134.20, \delta \mathrm{H}-125.67)$, which led to define the exact position of the hydroxyl group on the C13 (Figures S7 and S11).

We next performed a high-resolution scan of 13-HODE-G. Positive electrospray ionization mass spectrometry (ESI+) of 13-HODE-G yielded three main cations, i.e., the protonated molecule with loss of water $\left[\mathrm{M}-\mathrm{H}_{2} \mathrm{O}+\mathrm{H}\right]^{+}$at 353.2689 , as well as sodium adduct $[\mathrm{M}+\mathrm{Na}]^{+}$ at $m / z 393.2618$ and a potassium adduct $[\mathrm{M}+\mathrm{K}]^{+}$with $\mathrm{K}^{+}$at $m / z 409.2355$ (Figure 2B). The collision-induced decomposition (CID) of the $\left[\mathrm{M}-\mathrm{H}_{2} \mathrm{O}+\mathrm{H}\right]^{+}$ion at $m / z 353.2689$ yielded the predominant product ion at $m / z 261.2213$ ([13-HODE-G- $\mathrm{H}_{2} \mathrm{O}-$ glycerol] ${ }^{+}$), which is produced by loss of the hydroxyl group at $\mathrm{C} 13$ combined with the neutral loss of the glycerol (Figure 2C), as described for 2-AG [35]. 
Table 2. ${ }^{1} \mathrm{H}-\mathrm{NMR}$ and ${ }^{13} \mathrm{C}-\mathrm{NMR}$ data of $13-\mathrm{HODE}-\mathrm{G}$.

\begin{tabular}{|c|c|c|c|c|}
\hline \multirow{2}{*}{$\begin{array}{c}\text { CARBON } \\
\mathrm{N}^{\circ}\end{array}$} & \multicolumn{4}{|c|}{ 13-HODE-G (2) } \\
\hline & $\delta C(\mathrm{ppm})$ & $\delta \mathbf{H}(\mathrm{ppm})$ & Features & $\mathrm{J}(\mathrm{Hz})$ \\
\hline 1 & 174.3 & NA & NA & NA \\
\hline 2 & 34.1 & 2.35 & $\mathrm{t}$ & 7.5 \\
\hline 3 & 24.8 & $1.67-1.47$ & $2 \mathrm{H}$, br m & \\
\hline 4 & 22.6 & 1.32 & $\mathrm{~m}$ & \\
\hline 5 & 28.9 & 1.32 & $\mathrm{~m}$ & \\
\hline 6 & 28.9 & 1.32 & $\mathrm{~m}$ & \\
\hline 7 & 28.9 & 1.32 & $\mathrm{~m}$ & \\
\hline 8 & 27.6 & 2.18 & $\mathrm{~m}$ & \\
\hline 9 & 132.8 & 5.44 & $\mathrm{~m}$ & \\
\hline 10 & 127.8 & 5.98 & $\mathrm{t}$ & 10.9 \\
\hline 11 & 125.7 & 6.49 & $\mathrm{dd}$ & $15.2,11.0$ \\
\hline 12 & 135.9 & 5.67 & dd & $15.2,6.8$ \\
\hline 13 & 72.9 & 4.16 & $1 \mathrm{H}$, overlapped $\mathrm{m}$ & \\
\hline 14 & 37.3 & $1.67-1.47$ & $2 \mathrm{H}$, br m & \\
\hline 15 & 29.7 & 1.32 & $\mathrm{~m}$ & \\
\hline 16 & 29.3 & 1.32 & $\mathrm{~m}$ & \\
\hline 17 & 25.1 & 1.32 & $\mathrm{~m}$ & \\
\hline 18 & 14.1 & 0.89 & $\mathrm{t}$ & 7 \\
\hline $1^{\prime}$ & 70.3 & 3.93 & $1 \mathrm{H}, \mathrm{m}$ & \\
\hline $2^{\prime}$ & 65.2 & 4.16 & $2 \mathrm{H}$, overlapped $\mathrm{m}$ & \\
\hline $3^{\prime}$ & 63.3 & 3.65 & $2 \mathrm{H}, \mathrm{m}$ & \\
\hline
\end{tabular}

See Figure 1 for carbon number.

\subsection{Biosynthesis of 13-HODE-G by Human Recombinant 15-LO-1 and 15-LO-2}

We next assessed whether human recombinant 15-LO-1 and 15-LO-2 could biosynthesize 13-HODE-G from 1-LG, given that 2-LG is rapidly isomerized into 1-LG in the presence of water and that the experiments were done in aqueous buffers. In these experiments, the LA-induced 13-HODE synthesis was used as positive control (Figure 3A,E).

Both 15-LO-1 and 15-LO-2 biosynthesized 13-HODE-G from 1-LG (Figure 3B,F). At $10 \mu \mathrm{M} 1-\mathrm{LG}$, the efficacy of the reaction was $23 \%$ for $15-\mathrm{LO}-1$ and $40 \%$ for $15-\mathrm{LO}-2$. Of note, the 13-HODE-G:13-HODE ratio was 1:1 for both enzymes, indicating that they metabolized 1-LG and LA to comparable levels. (Figure 3C,G). Given that both enzymes can also biosynthesize 13-HODE-EA from LEA [21], we also tested the impact of a combination of LA, 1-LG, and LEA on the biosynthesis of 13-HODE, 13-HODE-G, and 13-HODE-EA, respectively. The combination of LA, 1-LG, and LEA led to the biosynthesis of 13-HODEEA > 13-HODE-G = 13-HODE for both 15-LO-1 and 15-LO-2 (Figure 3D,H). In these experiments, the incubation of 1-LG and/or LEA in absence of enzyme did not lead to the production of 13-HODE-G and/or 13-HODE-EA. 

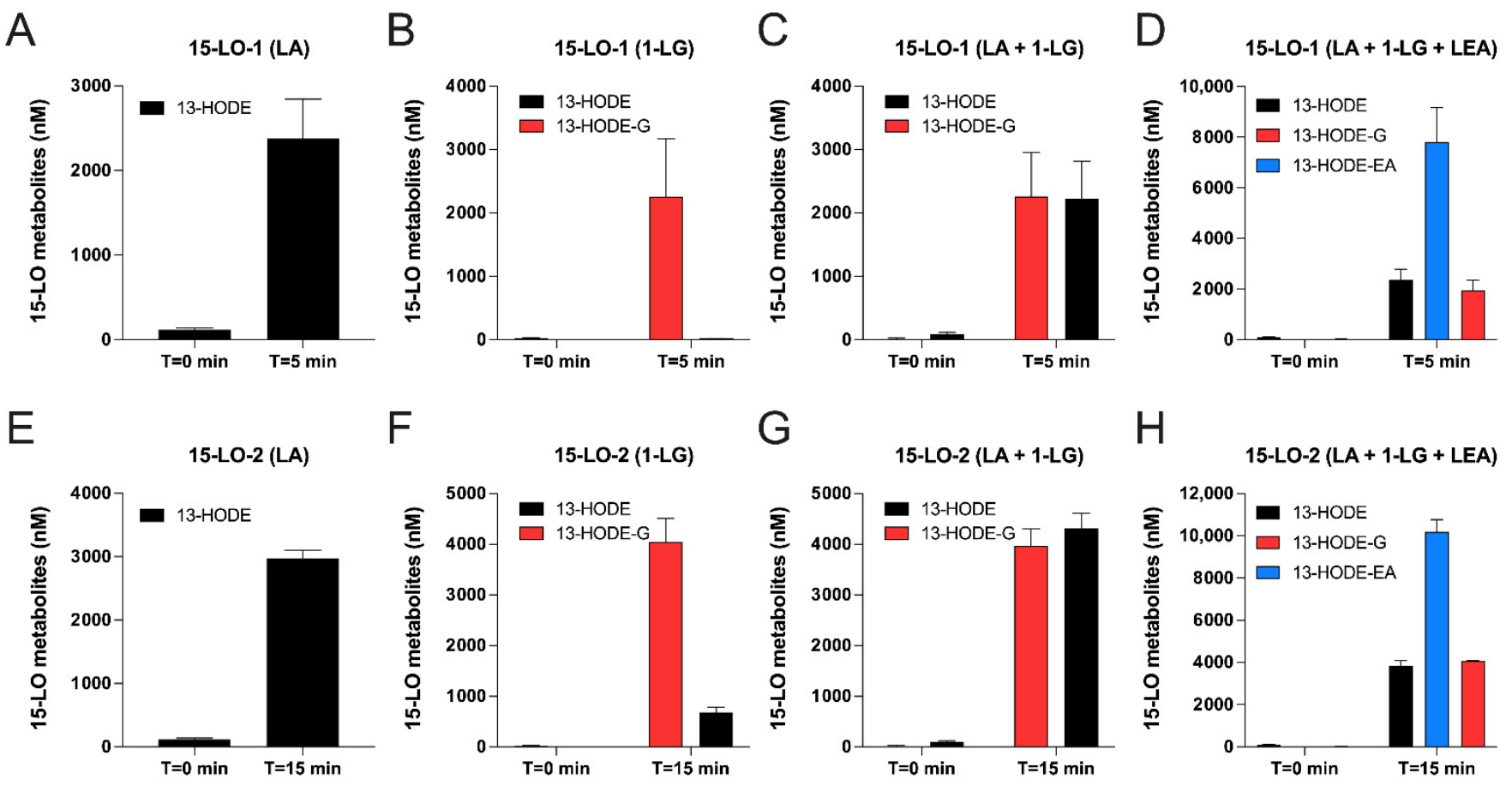

Figure 3. Metabolism of 1-LG, LA and LEA by human recombinant 15-LO-1 and 15-LO-2. Human recombinant 15-LO-1 (A-D) or 15-LO-2 (E-H) were incubated at $37^{\circ} \mathrm{C}$ in HEPES $25 \mathrm{mM}$ containing $0.01 \%$ triton. A total of $10 \mu \mathrm{M}$ of LA (A,D,E,H); 1-LG (B,D,F,H) or LEA (D,H) were added for $5 \mathrm{~min}$ (15-LO-1) or $15 \mathrm{~min}$ (15-LO-2). $\mathrm{NaBH}_{4}$ was then added for $5 \mathrm{~min}$ and incubations were stopped by the addition of $0.5 \mathrm{~mL}$ of cold $\left(-20^{\circ} \mathrm{C}\right) \mathrm{MeOH}$ containing $0.01 \%$ acetic acid and the internal standards. Samples then were processed for LC-MS/MS analyses as described in methods. Results are the mean ( \pm SEM) of 3 independent experiments.

\subsection{Human Eosinophils Metabolize LA, 1-LG, and LEA via the 15-LO Pathway}

Given the ability of human 15-LO enzymes to biosynthesize 13-HODE-EA and 13HODE-G from LEA and 1-LG, respectively ([21] and Figure 3), we next investigated if human eosinophils and neutrophils, which are recognized to biosynthesize 13-HODE in response to LA $[20,23,24]$, could also biosynthesize 13-HODE-EA and 13-HODE-G in response to their respective precursors. This possibility was very plausible, given that human eosinophils and neutrophils can metabolize the endocannabinoids 2-AG and AEA into their 15-hydroxylated derivatives $[18,20]$. To this end, we first treated human eosinophils with $3 \mu \mathrm{M}$ 1-LG, LEA or LA for 5 min (Figure 4). Human eosinophils metabolized 1-LG into 13-HODE-G and 13-HODE, with a predominance of 13-HODE (Figure 4A). This was expected as we previously reported that both 2-AG and 15-HETE-G were respectively hydrolyzed by human eosinophils into AA and 15-HETE, a phenomenon that was prevented by MAFP [36]. Furthermore, 1-LG and 13-HODE-G were also hydrolyzed by eosinophils, a phenomenon partially prevented by MAFP (data not shown). We thus repeated the experiment in the presence of MAFP, to prevent the hydrolysis of both 1-LG and 13-HODE-G. In agreement with the strong increase in 2-AG and 15-HETE-G half-life when their hydrolysis is inhibited [36], MAFP enhanced the 1-LG-induced biosynthesis of 13-HODE-G tenfold (Figure 4D), without affecting the biosynthesis of 13-HODE-EA induced by LEA and of 13-HODE induced by LA (Figure 4E,F). Consequently, and to better assess the biosynthesis of 13-HODE-G, all further experiments involving 1-LG were performed in presence of MAFP. Human eosinophils also biosynthesized 13-HODE-EA and 13-HODE in response to LEA (Figure 4B,E). As expected, human eosinophils metabolized LA into 13-HODE (Figure 4C,F). Of note, human eosinophils biosynthesized more 13-HODE than 13-HODEG or 13-HODE-EA, suggesting a better uptake of LA or a preferential metabolism of LA by eosinophils vs. exogenous 1-LG or LEA. 
A

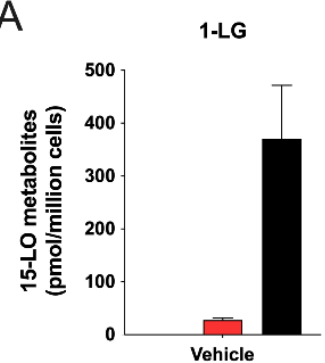

E

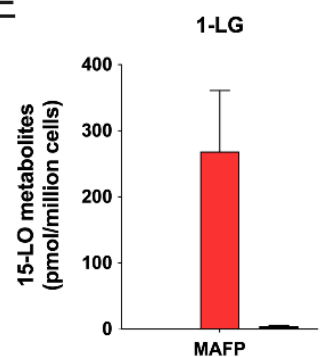

B

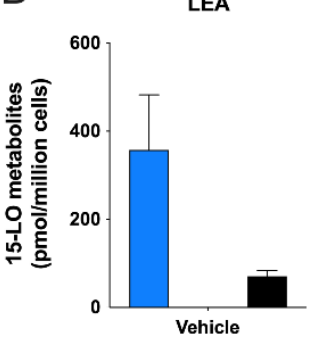

$\mathrm{F}$

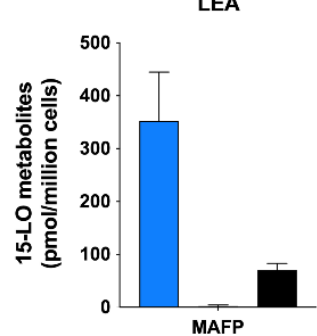

C

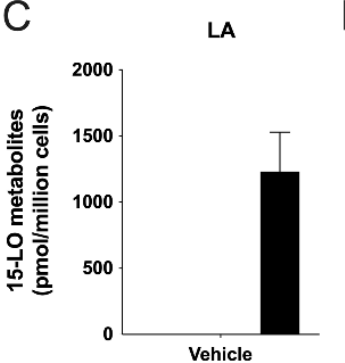

G

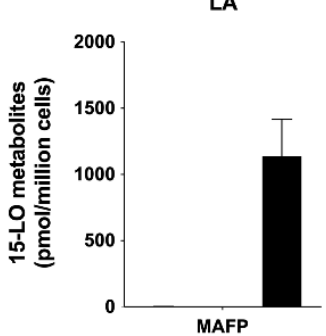

Figure 4. Metabolism of LA, 1-LG or LEA by human eosinophils. Pre-warmed human eosinophil suspensions $\left(37^{\circ} \mathrm{C}\right.$, $10^{6}$ cells $/ \mathrm{mL}$ in HBSS containing $1.6 \mathrm{mM} \mathrm{CaCl}_{2}$ ) were treated with DMSO (A-C) or MAFP $1 \mu \mathrm{M}(\mathbf{E}-\mathrm{G})$ for $5 \mathrm{~min}$ then stimulated with $3 \mu \mathrm{M}$ of $(\mathbf{A}, \mathbf{E})$ 1-LG, (B,F) LEA, (C,G) LA for another $5 \mathrm{~min}$. (D) Metabolite legend for panels. (A-G) Incubations were stopped by the addition of one volume of cold $\left(-20^{\circ} \mathrm{C}\right) \mathrm{MeOH}$ containing the internal standards. Samples then were processed for LC-MS analysis as described in methods. Results are the mean ( \pm SEM) of 4-5 independent experiments.

We next performed kinetic experiments to better establish the biosynthetic profiles of 13-HODE-G and 13-HODE-EA by human eosinophils, compared to that of 13-HODE. 1-LG, LEA, and LA at $3 \mu \mathrm{M}$ stimulated the biosynthesis of their 15-lipoxygenase metabolite in a time-dependent manner with maximal levels obtained after $15 \mathrm{~min}$, which was the longest time point studied (Figure $5 \mathrm{~A}-\mathrm{C}$ ). Of note, there was a small delay of $\sim 1 \mathrm{~min}$ before 1-LG and LEA were metabolized into their 15-lipoxygenase counterparts. This was not observed with the LA-induced 13-HODE biosynthesis. Concentration-response experiments showed that the biosynthesis of 13-HODE, 13-HODE-G, and 13-HODE-EA was concentration-dependent (Figure 5D-F). The biosynthesis of these metabolites could be detected with $100 \mathrm{nM}$ of substrate and was maximal at $10 \mu \mathrm{M}$, which was the highest concentration studied. Of note, neither 13-HODE, 13-HODE-G, nor 13-HODE-EA were detected in vehicle-treated eosinophils.

\subsection{Human Neutrophils Also Metabolize LA, 1-LG, and LEA into 13-Hydroxylated Compounds}

Human neutrophils are also capable of metabolizing fatty acids and endocannabinoids into their 15-LO derivatives, possibly via the 15-LO-2 and/or another unidentified enzyme [20]. We therefore tested if they would also metabolize 1-LG and LEA into their 13-HODE derivatives. Human neutrophils biosynthesized 13-HODE-G, 13-HODE-EA or 13-HODE in response to $3 \mu \mathrm{M}$ 1-LG, LEA or LA respectively (Figure 6A-C). In contrast to eosinophils, which produced high nM levels of the 15-lipoxygenase metabolites (Figures 4 and 5), neutrophils biosynthesized low nM levels of the investigated 15-LO metabolites. Moreover, and in agreement with their strong ability to hydrolyze 2-AG and 15-HETE-G in a MAFP-sensitive manner [36], 1-LG-treated neutrophils biosynthesized 20 times more 13-HODE-G and 65 times less 13-HODE in the presence of MAFP (Figure 6D). As for eosinophils, MAFP did not impact the ability of neutrophils to biosynthesize 13-HODE-EA and 13-HODE in response to LEA and LA, respectively (Figure 6E,F). While the treatment of human neutrophils with $3 \mu \mathrm{M}$ LA led to the exclusive biosynthesis of 13-HODE, the main product detected with the incubation with LEA was 13-HODE (ratio 13-HODE /13HODE-EA of $2.67 \pm 0.590$ ) and MAFP (which also inhibits the FAAH [37]) had no effect on this ratio. 13-HODE, 13-HODE-G, or 13-HODE-EA were not detected in vehicle-treated 
neutrophils. Furthermore, 1-LG and 13-HODE-G were also hydrolyzed by neutrophils, and this hydrolysis was prevented by MAFP (data not shown).

A

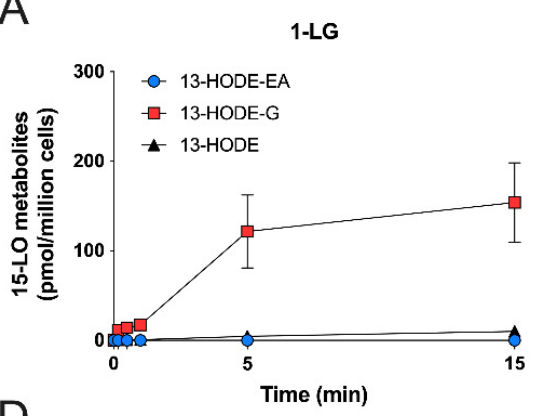

D

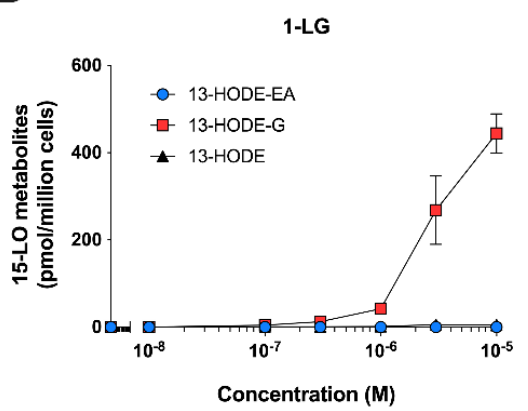

B

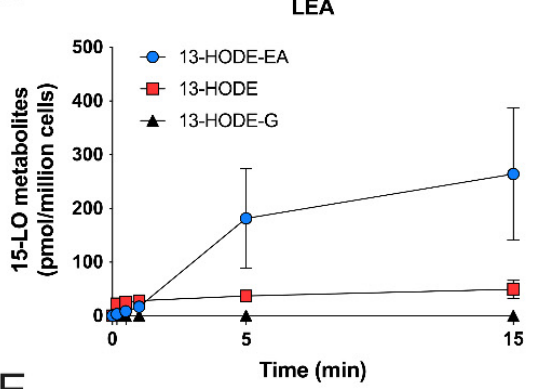

E

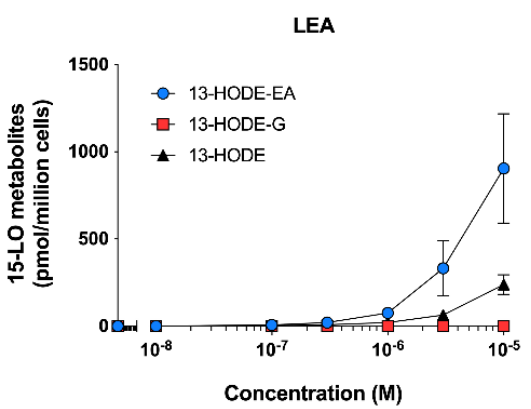

C

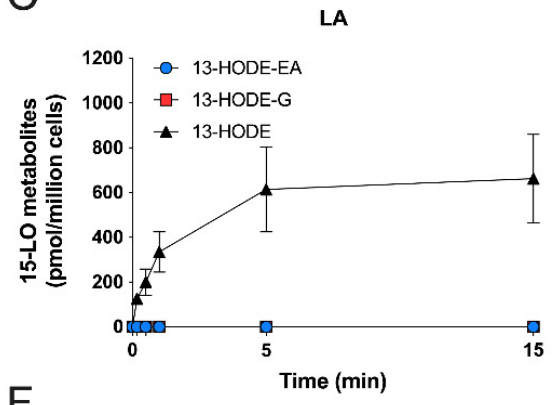

F

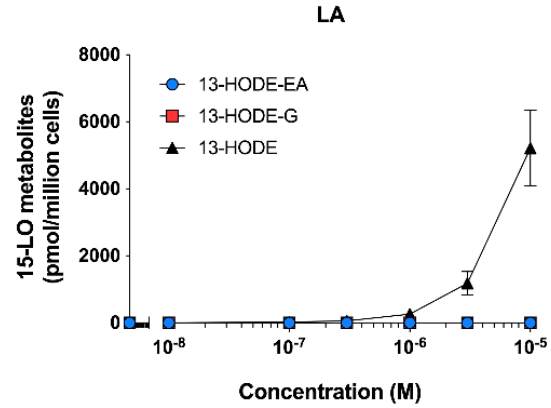

Figure 5. Time- and concentration-dependent synthesis of 15-LO metabolites from 1-LG, LEA, and LA by human eosinophils. Pre-warmed human eosinophils suspensions $\left(10^{6}\right.$ cells $/ \mathrm{mL}$ in HBSS containing $\left.1.6 \mathrm{mM} \mathrm{CaCl}_{2}\right)$ were treated with $3 \mu \mathrm{M}$ of (A) 1-LG, (B) LEA, or (C) LA for the indicated times. (D-F) Eosinophils were treated with increasing concentration of (D) 1-LG, (E) LEA or (F) LA for 5 min. In experiments involving 1-LG, cells were pretreated with MAFP for 5 min prior to the addition of 1-LG. Incubations were stopped by adding one volume of cold $\left(-20{ }^{\circ} \mathrm{C}\right) \mathrm{MeOH}$ containing the internal standards. Samples then were processed for LC-MS/MS analyses as described in methods. Data are the mean ( \pm SEM) of 4-5 independent experiments.

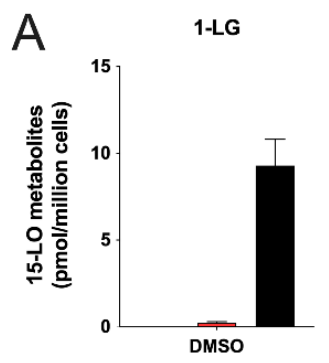

E

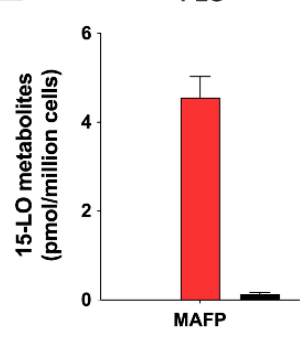

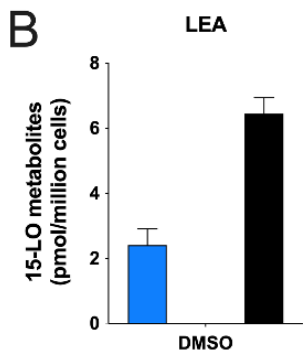

$\mathrm{F}$

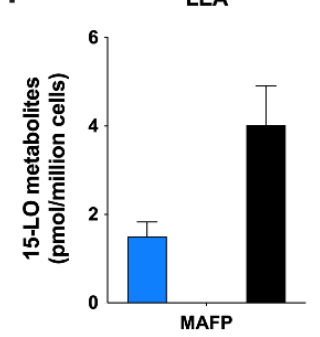

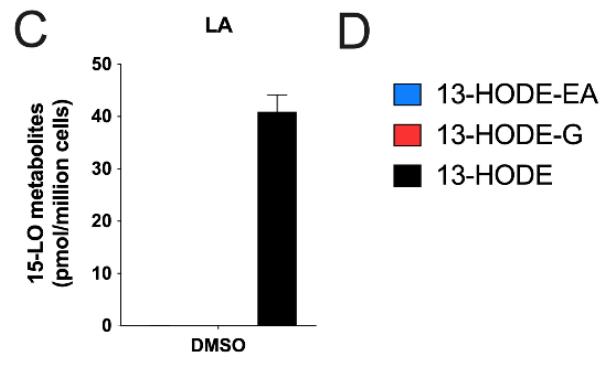

G

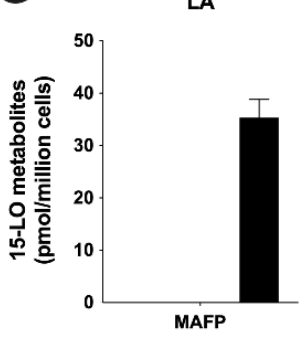

Figure 6. 15-LO metabolite production in response to LA, 1-LG, or LEA by human neutrophils. Pre-warmed human neutrophil suspensions $\left(37^{\circ} \mathrm{C}, 5 \times 10^{6}\right.$ cells $/ \mathrm{mL}$ in HBSS containing $1.6 \mathrm{mM} \mathrm{CaCl}_{2}$ ) were pre-treated with DMSO (A-C) or MAFP (E-G) for $5 \mathrm{~min}$ before the addition of $3 \mu \mathrm{M}$ of either (A,E) 1-LG, (B,F) LEA, (C,G) LA. (D) Metabolite legend for panels A-G. Incubations were stopped after $5 \mathrm{~min}$ by the addition of one volume of cold $\left(-20{ }^{\circ} \mathrm{C}\right) \mathrm{MeOH}$ containing the internal standards. Samples then were processed for LC-MS/MS analyses as described in methods. Results are the mean $( \pm \mathrm{SEM})$ of 4 independent experiments. 
We next performed kinetic and concentration-response experiments with human neutrophils to further characterize their ability to biosynthesize 13-HODE-G and 13-HODE-EA. The appearance of 13-HODE, 13-HODE-G, and 13-HODE-EA was much faster in neutrophils than in eosinophils, in line with our previous data using other 15-LO substrates [20]. Indeed, human neutrophils rapidly (10-30 s) biosynthesized 13-HODE derivatives upon their incubation with $3 \mu \mathrm{M}$ LA, 1-LG, or LEA (Figure 7). For the biosynthesis of 13-HODE-G and 13-HODE-EA, the levels remained relatively stable from 0.5 to 15 min (Figure 7A,B). In contrast, and as previously reported [20], the biosynthesis of 13-HODE in response to LA peaked at $10 \mathrm{~s}$, then slowly declined until $15 \mathrm{~min}$ (Figure 7C). Concentration-response experiments showed that the biosynthesis of 13-HODE, 13-HODE-G, and 13-HOGE-EA was also concentration-dependent in neutrophils (Figure 7D-F). The biosynthesis of these metabolites could be detected with $300 \mathrm{nM}$ of substrate and was maximal at $10 \mu \mathrm{M}$, which was the highest concentration investigated.

A

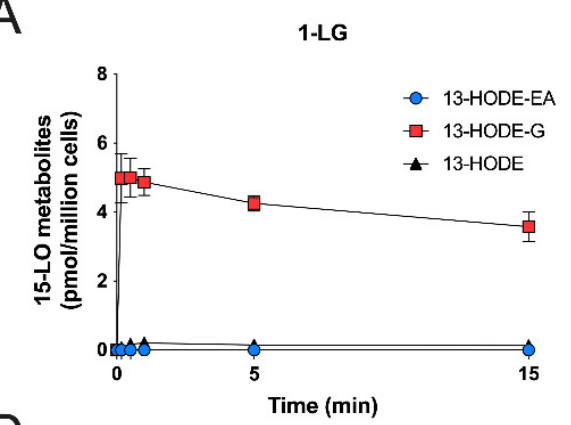

D

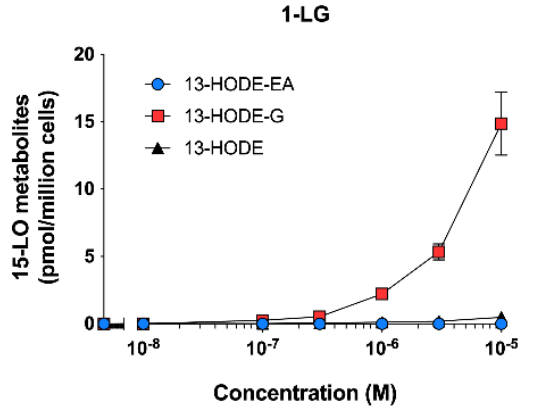

B

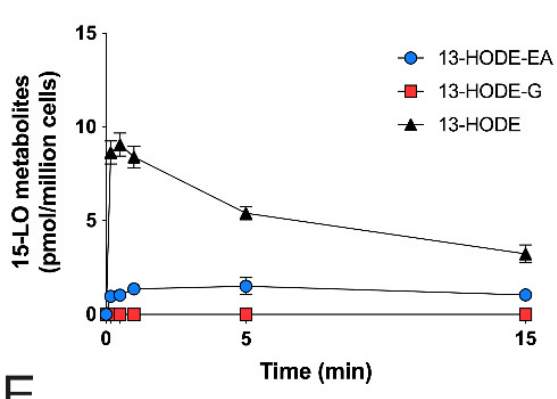

E

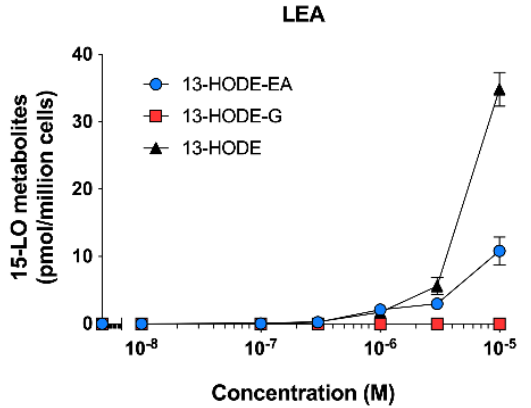

C

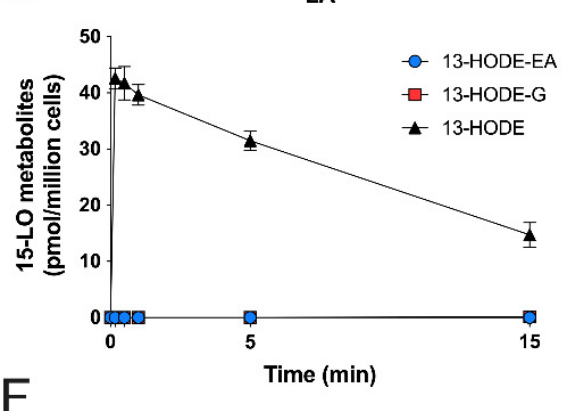

LA

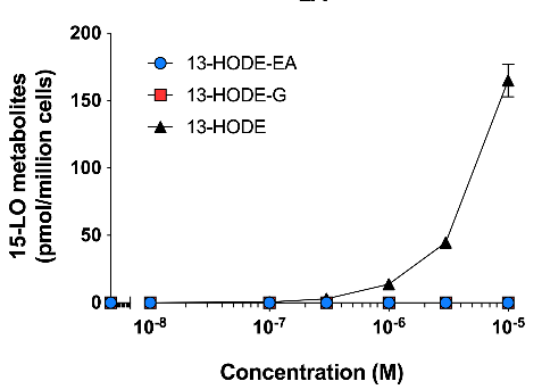

Figure 7. Time- and concentration-dependent biosynthesis of 15-LO metabolites from 1-LG, LEA, and LA by human neutrophils. Pre-warmed human neutrophils suspensions $\left(37^{\circ} \mathrm{C}, 5 \times 10^{6}\right.$ cells $/ \mathrm{mL}$ in $\mathrm{HBSS}$ containing $\left.1.6 \mathrm{mM} \mathrm{CaCl}_{2}\right)$ were treated with $3 \mu \mathrm{M}$ of (A) 1-LG, (B) LEA, or (C) LA for the indicated times. (D-F) Neutrophils were treated with increasing concentration of (D) 1-LG, (E) LEA, or (F) LA for $5 \mathrm{~min}$. In experiments involving 1-LG, cells were pretreated with $1 \mu \mathrm{M}$ MAFP for $5 \mathrm{~min}$ prior to the addition of 1-LG. Incubations were stopped by the addition of one volume of cold ( $\left.-20{ }^{\circ} \mathrm{C}\right)$ $\mathrm{MeOH}$ containing the internal standards. Samples then were processed for LC-MS/MS analyses as described in methods. Data are the mean $( \pm \mathrm{SEM})$ of 4 independent experiments.

\subsection{Substrate Preference of Eosinophils and Neutrophils}

We recently showed that when investigating the biosynthesis of 15-LO metabolites by eosinophils and neutrophils, combining different substrates together does not drastically impact substrate preference vs. recombinant enzymes [20]. We thus performed another series of experiments in which we treated eosinophils and neutrophils from the same donors with a combination of LA, 1-LG, and LEA, at $3 \mu \mathrm{M}$ each (Figure 8). Eosinophils were consistently better at converting the three substrates than neutrophils, with $\sim 500$ times more 13-HODE-EA, 60 times more 13-HODE-G, and 30 times more 13-HODE. Interestingly, the 13-HODE:13-HODE-EA:13-HODE-G ratio was 6:3:1 for MAFP-treated eosinophils and 30:1:3 for neutrophils, supporting the above finding that among the LA-containing lipids we tested, LA was most strongly metabolized by the two cell types. 

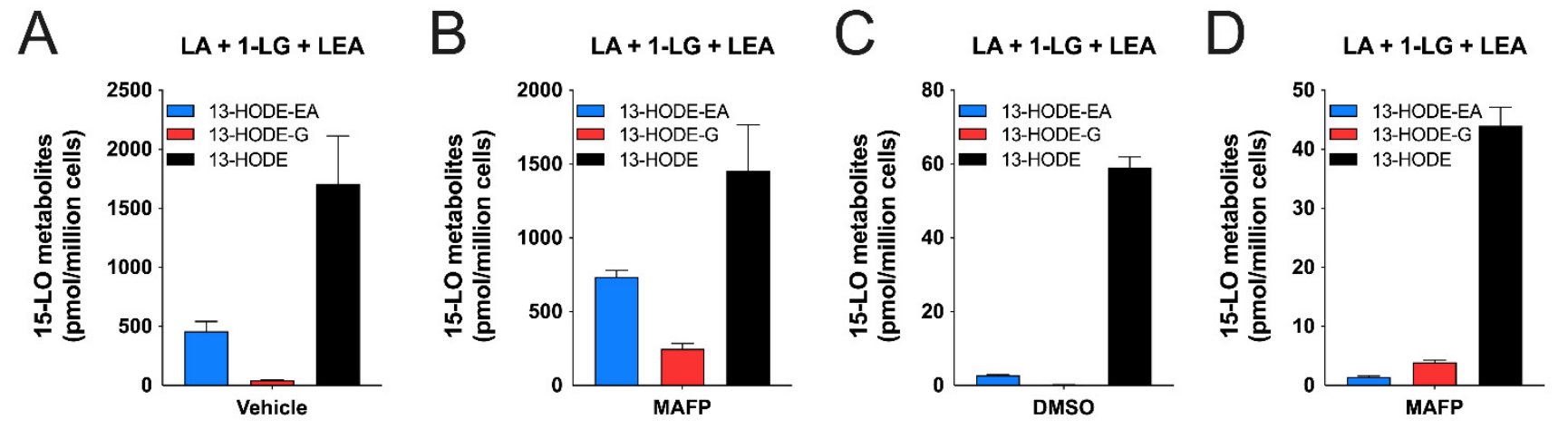

\section{Eosinophils}

Neutrophils

Figure 8. Substrate preference by human eosinophils and neutrophils. Pre-warmed $\left(37^{\circ} \mathrm{C}\right)$ human eosinophil suspensions $\left(10^{6}\right.$ cells $/ \mathrm{mL}$ in HBSS containing $\left.1.6 \mathrm{mM} \mathrm{CaCl}_{2}\right)$ or neutrophil suspensions $\left(5 \times 10^{6}\right.$ cells $/ \mathrm{mL}$ in HBSS containing $1.6 \mathrm{mM}$ $\mathrm{CaCl}_{2}$ ) were pre-treated with DMSO $(\mathbf{A}, \mathbf{C})$ or MAFP $(\mathbf{B}, \mathbf{D})$ for $5 \mathrm{~min}$ before the addition of a mixture of 1-LG, LEA, and LA at $3 \mu \mathrm{M}$ each. Incubations were stopped after $5 \mathrm{~min}$ by the addition of one volume of cold $\left(-20{ }^{\circ} \mathrm{C}\right) \mathrm{MeOH}$ containing the internal standards. Samples then were processed for LC-MS/MS analyses as described in methods. Results are the mean $( \pm \mathrm{SEM})$ of 4 independent experiments.

\subsection{Inhibition of 13-HODE-EA and 13-HODE-G Biosynthesis by BLX-3887 and NDGA}

We next investigated if the biosynthesis of 13-HODE-EA and 13-HODE-G was the consequence of 15-LO-1 activity by performing a series of experiments in presence of the 15-LO-1-selective inhibitor BLX-3887 [38] or the LO inhibitor NDGA [39,40]. As expected, the treatment of eosinophils with BLX-3887 $(10 \mu \mathrm{M})$ strongly inhibited the 1-LG-induced 13-HODE-G biosynthesis by 75\% and the LEA-induced 13-HODE-biosynthesis by 95\% (Figure 9A,B). In contrast, the incubation of neutrophils with BLX-3887 or NDGA did not inhibit the biosynthesis of the investigated 15-LO metabolites (Figure 9C,D). This was expected as we previously reported, as BLX-3887 and NDGA did not inhibit the biosynthesis of 15-LO metabolites from exogenously added fatty acids in neutrophils [20].
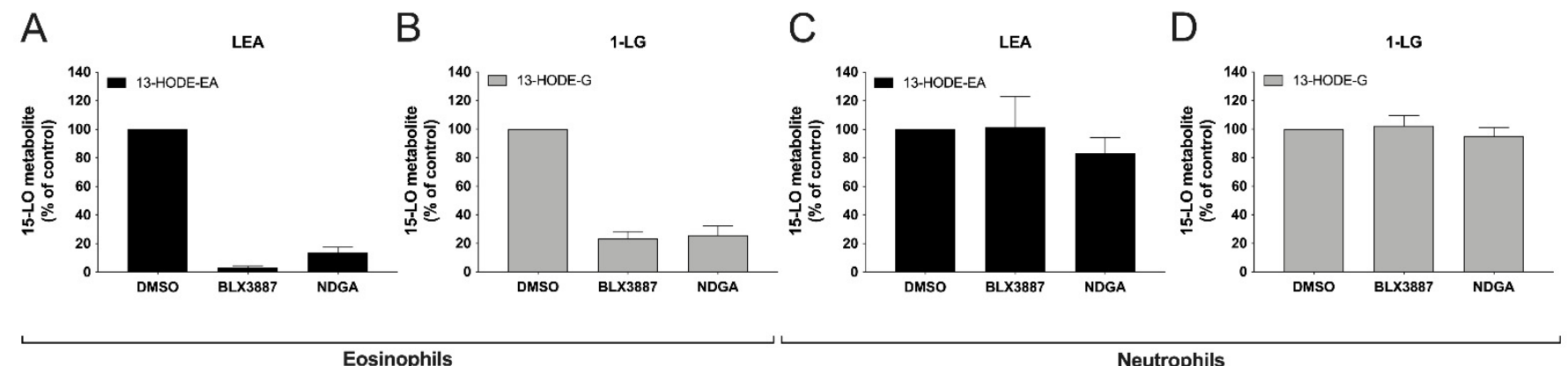

Eosinophils

Neutrophils

Figure 9. Inhibition of 13-HODE-G and 13-HODE-EA biosynthesis by 15-LO inhibitors in human eosinophils and neutrophils. Pre-warmed $\left(37^{\circ} \mathrm{C}\right)$ human $(\mathbf{A}, \mathbf{B})$ eosinophil suspensions $\left(10^{6}\right.$ cells $/ \mathrm{mL}$ in $\mathrm{HBSS}$ containing $\left.1.6 \mathrm{mM} \mathrm{CaCl}_{2}\right)$ or $(\mathbf{C}, \mathbf{D})$ neutrophil suspensions $\left(5 \times 10^{6}\right.$ cells $/ \mathrm{mL}$ in HBSS containing $\left.1.6 \mathrm{mM} \mathrm{CaCl} \mathrm{C}_{2}\right)$ were pre-treated with DMSO, BLX-3887 $(10 \mu \mathrm{M})$ or NDGA $(10 \mu \mathrm{M})$ for 5 min before the addition of $3 \mu \mathrm{M}(\mathbf{A}, \mathbf{C})$ LEA or (B,D) 1-LG. Incubations were stopped $5 \mathrm{~min}$ after LEA or 1-LG treatment by the addition of one volume of cold $\left(-20^{\circ} \mathrm{C}\right) \mathrm{MeOH}$ containing the internal standards. Samples then were processed for LC-MS/MS analyses as described in methods. Results are the mean ( \pm SEM) of 4 independent experiments.

\subsection{Detection of $13-H O D E-G$ In Vivo}

We previously documented that 13-HODE-EA was found in human saliva and skin samples [21]. While we could not detect 13-HODE-G in human saliva samples, we found this metabolite in human epidermis samples $(21.9 \pm 6.2 \mathrm{fmol} / \mathrm{mg}$ tissue, mean $\pm \mathrm{SEM}$, 
$n=5$ ). Furthermore, $13-$ HODE-G was found in other tissues from mice, notably the gastrointestinal tract (Table 3), the liver and the adipose tissue [41], indicating that 13HODE-G is also an endogenous mediator.

Table 3. Levels of 13-HODE-G (in fmol/mg of tissue \pm SEM) in the gastrointestinal tract of mice.

\begin{tabular}{cccc}
\hline Duodenum & Jejunum & Ileum & Caecum \\
\hline $9746 \pm 4360$ & $4810 \pm 2692$ & $1165 \pm 185$ & $997 \pm 317$ \\
\hline
\end{tabular}

\subsection{Binding Assays}

We next sought to determine whether 13-HODE-G could bind/activate receptors belonging to the endocannabinoidome, notably the $\mathrm{CB}_{1}, \mathrm{CB}_{2}$, and $T R P V_{1}$, as well as PPAR- $\alpha$ and $-\gamma$. Given that 13-HODE-G appears to be rapidly hydrolyzed into 13-HODE (Figures 4, 6 and 8), we also tested the impact of 13-HODE in our different assays. To this end, we first performed binding assays for the $C_{1}$ and $C_{2}$ receptors. While 1-AG was bound to both receptors, 1-LG was only bound to the $\mathrm{CB}_{1}$ receptor. In contrast, neither 13HODE nor 13-HODE-G exhibited any binding affinity for the $\mathrm{CB}_{1}$ and $\mathrm{CB}_{2}$ receptors up to $10 \mu \mathrm{M}$ (Table 4). As for TRPV 1 , while 1-AG and 1-LG displayed functional activity toward this channel, neither 13-HODE-G nor 13-HODE activated that receptor again (Table 5). Finally, 13-HODE-G did not stimulate the transcriptional activity of PPAR- $\alpha$ or $-\gamma$, in contrast to robust effect of 13-HODE on PPAR- $\alpha$ (Figure 10B).

Table 4. Affinity of 13-HODE-G and related compounds for human recombinant $\mathrm{CB}_{1}$ and $\mathrm{CB}_{2}$ receptors. Results are shown as the mean $\pm \mathrm{SD}$.

\begin{tabular}{|c|c|c|c|c|c|c|}
\hline \multirow[b]{2}{*}{ Compound } & \multicolumn{3}{|c|}{$\mathrm{CB}_{1}$ Receptor } & \multicolumn{3}{|c|}{$\mathrm{CB}_{2}$ Receptor } \\
\hline & $\begin{array}{l}\mathrm{IC}_{50} \\
(\mu \mathrm{M})\end{array}$ & $\underset{(\mu \mathrm{M})}{\mathbf{K i}}$ & $\begin{array}{l}\text { Max Tested } \\
\text { (\% Displacement) }\end{array}$ & $\begin{array}{l}\mathrm{IC}_{50} \\
(\mu \mathrm{M})\end{array}$ & $\begin{array}{c}\mathrm{Ki} \\
(\mu \mathrm{M})\end{array}$ & $\begin{array}{c}\text { Max Tested } \\
\text { (\% Displacement) }\end{array}$ \\
\hline 13-HODE & $>10$ & $>10$ & $\begin{array}{c}10 \mu \mathrm{M} \\
(7.56 \pm 2.3)\end{array}$ & $>10$ & $>10$ & $\begin{array}{c}10 \mu \mathrm{M} \\
(38.34 \pm 5.4)\end{array}$ \\
\hline 13-HODE-G & $>10$ & $>10$ & $\begin{array}{c}10 \mu \mathrm{M} \\
(18.90 \pm 6.1)\end{array}$ & $>10$ & $>10$ & $\begin{array}{c}10 \mu \mathrm{M} \\
(33.58 \pm 21.3)\end{array}$ \\
\hline $1-\mathrm{AG}$ & $1.32 \pm 0.46$ & $0.15 \pm 0.05$ & $\begin{array}{c}10 \mu \mathrm{M} \\
(90.4 \pm 1.3)\end{array}$ & $1.02 \pm 0.04$ & $0.16 \pm 0.01$ & $\begin{array}{c}10 \mu \mathrm{M} \\
(75.52 \pm 2.4)\end{array}$ \\
\hline 1-LG & $2.81 \pm 0.85$ & $0.31 \pm 0.15$ & $\begin{array}{c}10 \mu \mathrm{M} \\
(95.8 \pm 16.4)\end{array}$ & $>10$ & $>10$ & $\begin{array}{c}10 \mu \mathrm{M} \\
(28.45 \pm 9.4)\end{array}$ \\
\hline
\end{tabular}

Table 5. Effect of 13-HODE-G and related compounds on human recombinant $\mathrm{TRPV}_{1}$-mediated intracellular calcium elevation. Results are shown as the mean \pm SD. ${ }^{1}$ Desensibilization was assayed using $100 \mathrm{nM}$ capsaicin.

\begin{tabular}{cccc}
\hline Compound & $\begin{array}{c}\text { Efficacy } \\
\text { (\% Max Response) }\end{array}$ & $\begin{array}{c}\text { Potency } \\
\left(\text { EC }_{\mathbf{5 0}} \text { in } \boldsymbol{\mu M}\right)\end{array}$ & $\begin{array}{c}\text { Desensibilization } \mathbf{1}^{2} \\
\left(\mathbf{I C}_{\mathbf{5 0}} \text { in } \boldsymbol{\mu M}\right)\end{array}$ \\
\hline 1-AG & $58.9 \pm 1.2$ & $0.39 \pm 0.03$ & $1.1 \pm 0.1$ \\
1-LG & $46.5 \pm 0.9$ & $0.23 \pm 0.02$ & $2.7 \pm 0.3$ \\
13-HODE & $<10$ & - & $>50$ \\
13-HODE-G & $<10$ & - & $>50$ \\
\hline
\end{tabular}


A

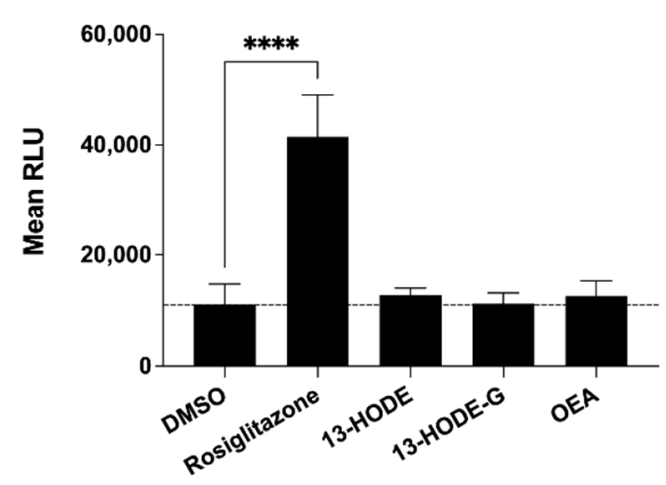

B

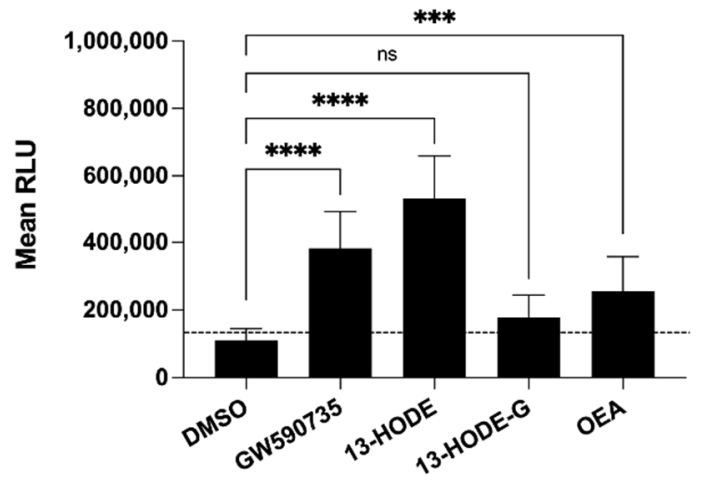

Figure 10. Impact of 13-HODE and 13-HODE-G on PPAR activity. Cells were incubated with $30 \mu \mathrm{M}$ 13-HODE, 13-HODE-G, or OEA overnight and PPAR activity was measured using the PPAR assay kits according to the manufacturers' instructions. Rosiglitazone $(10 \mu \mathrm{M})$ and GW $590735(100 \mathrm{nM})$ were utilized as positive controls for the (A) PPAR- $\gamma$ and (B) PPAR- $\alpha$ assays, respectively. Data represent the mean ( \pm SEM) of three (PPAR- $\gamma$ ) or five (PPAR- $\alpha$ ) experiments, each performed in triplicates. $p$ values were obtained by performing a 2-way ANOVA with a Sidak multiple comparison tests. ${ }^{* * *} p<0.0001$, *** $p<0.001$. ns: $p>0.05$.

\subsection{Theoretical Complex of PPAR $\alpha$ with 13-HODE}

To get insight into the binding mode of 13-HODE into PPAR $\alpha$ ligand binding domain (LBD) a molecular docking plus molecular dynamics simulations has been carried out. Two docking starting poses, i.e., pose I and pose II, sharing the orientation of the carboxylate group, which points toward the polar residues in the LBD, that is His440 (helix H10/11), Ser208 (Helix H3), and Tyr464 (helix H12), but differing in the conformation of the alkyl chain, were selected for the subsequent molecular dynamics simulations. The representative frames from molecular dynamics for each pose are shown in Figure 11. Both poses stably engages a network of H-bonds between the carboxylic group and His440 (helix H10/11), Ser208 (Helix H3), Tyr314 (helix H5), and Tyr464 (helix H12), a residue critical for a complete activation of PPAR- $\alpha$, while the hydroxyl group forms a stable H-bond either with Cys276 or Thr279 (helix H3) sidechain in pose I and pose II, respectively (Figure 11). The alky chain is hosted in the hydrophobic pocket formed by the helix bundle and the $\beta$-sheet and wraps around helix $\mathrm{H} 3$ in a horseshoe conformation.
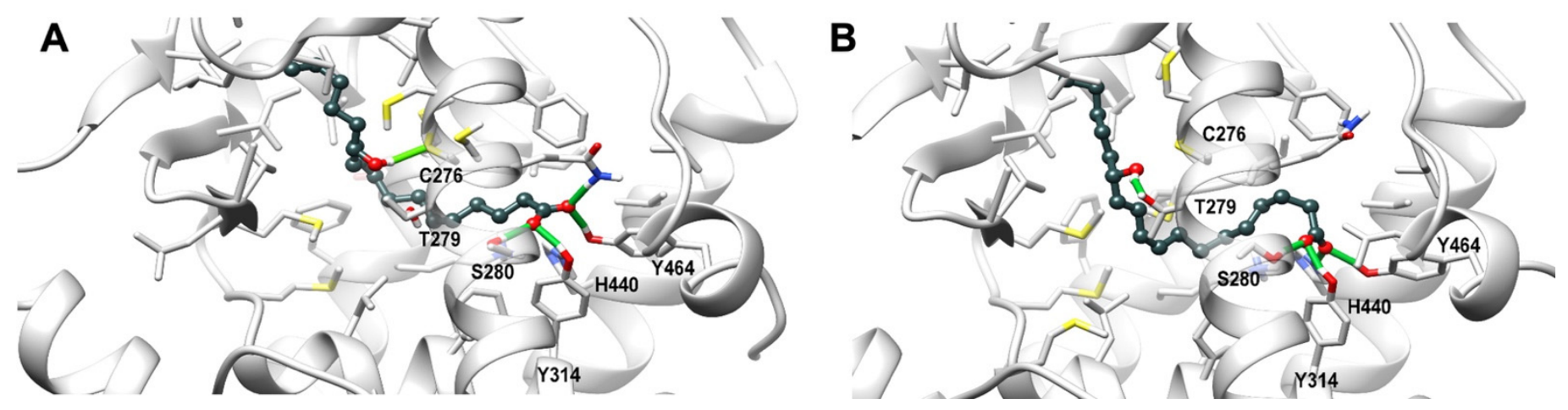

Figure 11. Representative frames from molecular dynamics of PPAR $\alpha$ (light gray) in complex with 13-HODE (dark grey) shown in ball and stick representation. Panel $(\mathbf{A}, \mathbf{B})$ show the docking pose I and pose II of the ligand, respectively. Protein residues within $5 \AA$ from the ligands are shown in stick representation. H-bonds are shown as green stick. Hydrogen, nitrogen, oxygen, and sulfur atom are painted white, blue, red, and yellow, respectively. A transparent surface for ribbons was used wherever they hide the ligand-binding site. 


\section{Discussion}

Over the last forty years, several studies have been documenting that the 15-LO pathway participates in the biosynthesis of numerous oxylipins from various substrates. However, while it has been documented that $15-\mathrm{LO}$ enzymes can metabolize the endocannabinoids 2-AG and AEA into 15-HETE-G and 15-HETE-EA, respectively [1,18,20,42], there is a knowledge gap regarding the biosynthesis of 15-LO-derived metabolites of other monoacylglycerols and $\mathrm{N}$-acyl-ethanolamines, the lipid families to which 2-AG and AEA belong. In this regard, we recently documented the metabolism of the endocannabinoidome mediator LEA into 13-HODE-EA by human recombinant 15-LO-1 and 15-LO-2 [21]. In this study, we aimed at documenting if 1-LG could also be metabolized by the 15-LO pathway and if LEA and 1-LG could be metabolized by 15-LO-expressing leukocytes.

The data presented herein show that (1)1-LG and 1-LG- $\mathrm{d}_{5}$ can be synthesized using soybean LO into 13-HODE-G and 13-HODE-G- $\mathrm{d}_{5}$, respectively; (2) recombinant 15-LO-1 and 15-LO-2 have the ability to metabolize 1-LG into 13-HODE-G; (3) human eosinophils and neutrophils metabolize LEA into 13-HODE-EA and 1-LG into 13-HODE-G in a timeand concentration-dependent manner; (4) the biosynthesis of 13-HODE-G can only be correctly assessed in presence of the serine hydrolase inhibitor MAFP in both eosinophils and neutrophils; (5) in presence of an equal concentrations of substrates, the ratio of 13-HODE:13-HODE-EA:13-HODE-G biosynthesis was 6:3:1 in eosinophils and 30:3:1 in neutrophils; (6) the biosynthesis of the investigated 15-LO metabolites was blocked by the 15-LO-1 inhibitor BLX3887 in eosinophils but not in neutrophils; (7) 13-HODE-G is very weakly active or inactive at targets shown previously and here to be activated by its parent compound. 1-LG, i.e., $\mathrm{CB}_{1}, \mathrm{CB}_{2}, \mathrm{TRPV}_{1}$, and PPAR- $\alpha$ or $-\gamma$, whereas $13-\mathrm{HODE}$ was found here to activate PPAR- $\alpha$; and (8) $13-\mathrm{HODE}-\mathrm{G}$ was found in numerous tissues from mice and humans.

Odaneth and colleagues previously showed that stearoyl-glycerol synthesis was successfully achieved by performing an esterification using glycerol and stearic acid [25]. Herein, we adapted this strategy that was key for the synthesis of 1-LG- $\mathrm{d}_{5}$, the latter being commercially unavailable. This latter compound was then used here for the quantitative analysis of 1-LG by LC-MS/MS. The yield was very good ( $\sim 90 \%)$ and $1-L G-\mathrm{d}_{5}$ was easily separated from LA by RP-HPLC. In addition, we provide compelling evidence that soybean lipoxygenase allows the synthesis of $13-$ HODE-G and 13-HODE-G- $\mathrm{d}_{5}$ from 1-LG and 1-LG- $\mathrm{d}_{5}$, respectively. The yields of the reactions were lower, under the experimental conditions described, than what we reported for 13-HODE-EA ( 45\%; [21]). Indeed, the reaction of 1-LG with soybean lipoxygenase also led to the production of 13-HODE and $\mathrm{LA}$, indicating that the basic conditions in which the reaction occurs $(\mathrm{pH}=12)$, results in the chemical hydrolysis of 1-LG into LA and glycerol. Whether 13-HODE-G is hydrolyzed into 13-HODE under basic conditions has not been explored in depth to date. However, the detection of 13-HODE and LA in our reaction mixtures indicates that $\mathrm{pH}$ might be an important issue to consider, notably for the long-term storage of purified 13-HODE-G (and 13-HODE-G-d 5 ).

The results obtained here with human recombinant 15-LO-1 and -2 data (Figure 3) indicated that both enzymes metabolize 1-LG and LA to the same extent. Interestingly, when added simultaneously, LEA was preferentially metabolized over LA and 1-LG by either enzyme. This finding is consistent with those of our previous publication, in which we observed a 13-HODE-EA/13-HODE ratio of $~ 3.5$ for 15-LO-1 and $~ 3$ for 15-LO-2 [21], and is also in agreement with the data from Ivanof et al. who found that human 15-LOs better oxidized AEA over AA [43]. While Ivanof also documented a slight preference of 2-AG vs. AA, we did not observe such preference for 1-LG vs. LA, under the conditions utilized. Further enzymatic experiments $\left(\mathrm{V}_{\max }\right.$ and $\mathrm{K}_{\mathrm{m}}$ calculations) would be a key addition to further characterize the substrate preference of 15-LO-1 and 15-LO-2.

Human eosinophils and neutrophils biosynthesized 13-HODE-G in response to 1LG in a time- and concentration-dependent manner (Figures 5 and 7). This biosynthesis was dramatically enhanced by the serine hydrolase inhibitor MAFP in both cell types 
(Figures 4,6 and 8). This was expected as we previously showed that the 15-LO metabolite of 2-AG, 15-hydroxy-eicosatetraenoyl-glycerol, was hydrolyzed to the same extent as 2-AG in both neutrophil and eosinophil suspensions, a phenomenon that was prevented by MAFP [36]. Herein, MAFP also diminished and or prevented the hydrolysis of 13-HODE-G and 1-LG by eosinophils and neutrophils (data not shown). This indicates that MAFP also interferes with the hydrolysis of both 1-LG and 13-HODE-G, and that preventing such a reaction increases the levels of these compounds in cellulo and possibly in vivo, as previously suggested $[27,36]$.

Human eosinophils and neutrophils also biosynthesized 13-HODE-EA in response to LEA. This was not modulated by MAFP, in agreement with the inability of the latter to enhance the AEA-induced 15-HETE-EA biosynthesis [20]. However, different biosynthetic profiles were observed when comparing human eosinophils and neutrophils. Indeed, while LEA-stimulated eosinophils biosynthesized 13-HODE-EA and 13-HODE in a 5.3:1 ratio, LEA-stimulated neutrophils biosynthesized 13-HODE-EA and 13-HODE in 1:0.37 ratio (Figures 4 and 6). The hydrolysis of 13-HODE-EA into 13-HODE is very unlikely the main cause of 13-HODE presence in LEA-treated neutrophils, as 13-HODE-EA was not hydrolyzed rapidly, with $60 \%$ remaining after $15 \mathrm{~min}$. 13-HODE-EA was even more stable in our eosinophil preparation with $90 \%$ of the added 13-HODE-EA remaining after $15 \mathrm{~min}$, although this difference might be the consequence of a lower cell concentration of eosinophils $\left(10^{6}\right.$ cells $\left./ \mathrm{mL}\right)$ vs. neutrophils $\left(5 \times 10^{6}\right.$ cells $\left./ \mathrm{mL}\right)$. Another explanation for the presence of 13-HODE in these reactions is, therefore, that LEA is hydrolyzed into LA, and then metabolized into 13-HODE. However, the half-life of LEA and the production of LA was similar between neutrophils and eosinophils. Furthermore, when we incubated eosinophils with the 15-LO-1 specific inhibitor BLX-3887 and LEA, we inhibited the biosynthesis of 13-HODE-EA, but not that of 13-HODE, suggesting that the production of 13-HODE from LEA is not 15-LO-1-dependent. It was previously reported that LA can be oxidized into 13-HpODE, a precursor of 13-HODE, but this process was reported after longer incubations with LA than the 15 min time point we evaluated [44]. The incubation of eosinophils and neutrophils led to a small release of LA (150 and $30 \mathrm{pmol} / \mathrm{million}$ cells respectively) Thus, we cannot exclude that this 13-HODE production in LEA-treated neutrophils and eosinophils is the consequence of a non-enzymatic oxidation of LA nor can we exclude a potential role of the NAAA, which is not inhibited by MAFP.

In experiments in which MAFP-treated human eosinophils were independently treated with LA, LEA, or 1-LG, they biosynthesized 13-HODE, 13-HODE-EA, and 13HODE-G at a 4:1:1 ratio (Figure 4). When the experiments were repeated by simultaneously treating human eosinophils with a combination of LA, LEA, and 1-LG, the 13-HODE:13HODE-EA:13-HODE-G ratio was 6:3:1 (Figure 8). This indicates that human eosinophils better metabolize LA vs. LEA and 1-LG. This finding was unexpected, as it is in sharp contrast with the data obtained with human recombinant 15-LO-1 (Figure 3). Interestingly, our kinetic experiments showed that in contrast to the LA-induced 13-HODE biosynthesis, the 1-LG-induced 13-HODE-G and the LEA-induced 13-HODE-EA biosynthesis were delayed by $\sim 1$ min (Figure 5). Such a delay was previously observed by our group when we compared the AA- and the 2-AG-induced leukotriene $\mathrm{B}_{4}$ biosynthesis in human neutrophils [13]. This raises the possibility that like 2-AG, 1-LG and LEA do not penetrate/diffuse into eosinophil cell membranes as rapidly as LA and that perhaps, a cellular membrane transporter is needed to shuttle 1-LG/LEA within the cells, compared to fatty acids. It could also indicate that 1-LG or LEA do not reach the cellular 15-LO-1-containing compartments as rapidly as LA.

Human neutrophils also biosynthesized 13-HODE-G and 13-HODE-EA in response to 1-LG and LEA, respectively in a concentration-dependent manner. As for human eosinophils, MAFP was key for the assessment of 13-HODE-G biosynthesis. Moreover, LA was also a better substrate for neutrophils compared to 1-LG and LEA. Aside from these similarities, we also observed major differences between eosinophils and neutrophils. First, neutrophils produced around 100 times less 15-LO metabolites compared to eosinophils, in 
agreement with our previous study assessing the biosynthesis of 15-LO metabolites from fatty acids and endocannabinoids [20]. Second, the biosynthesis of 13-HODE, 13-HODE-G, and 13-HODE-EA was very rapid, reaching a maximal accumulation at $15 \mathrm{~s}$ and slowly decaying overtime (Figure 7), in contrast to eosinophils in which a delay was observed for the biosynthesis of 13-HODE-G and 13-HODE-EA. Furthermore, the biosynthesis of these mediators was not inhibited by the 15-LO-1 inhibitor BLX3887 (Figure 9). This is perfectly in line with our earlier study in which eosinophil-depleted neutrophils (which were also utilized herein) biosynthesized 15-LO metabolites, a phenomenon that was not prevented by 15-LO-1 inhibitors and poorly prevented by NDGA [20]. But again, we cannot exclude that the biosynthesis of 13-HODE, 13-HODE-G, and 13-HODE-EA by neutrophils is the consequence of a non-enzymatic oxidation of LA, 1-LG, and LEA respectively. Given that 15-LO-2 inhibitors are not commercially available, we did not investigate their involvement.

The binding/functional assays performed with a subset of endocannabinoidomerelated receptors did not allow us to pinpoint which receptor is activated by 13-HODE$G, G$, while we have previously shown that TRPV1 is a receptor for 13-HODE-EA [21]. Nonetheless, we found that 13-HODE is a good PPAR- $\alpha$ agonist, in agreement with a recent study from Kämmerer and colleagues [45]. This was also supported by the in silico analysis, where 13-HODE adopts a binding conformation in which the carboxylate group engages a network of stable H-bonds with the polar residue Ser280, Tyr314, His440, and Tyr464 sidechains, while the hydroxyl group is alternatively involved in a H-bond with Thr279 and Cys276 (Figure 11). The carboxylate H-bond network strongly contributes to the binding/activation of PPAR- $\alpha$, an effect that is shared with canonical agonists, but hampered in 13-HODE-G, where the esterification by a glycerol moiety both deletes the negative charge and introduces steric clashes in the 13-HODE moiety arrangement. However, 13-HODE-G was found in almost all mouse tissues that we analyzed. Interestingly, we found that 13-HODE-G levels are reduced in the liver of $o b / o b$ compared to $d b / d b$ and lean mice [41], possibly suggesting its role in obesity-induced hepatic disorders (e.g., fatty liver and accompanying inflammation).

\section{Conclusions}

In conclusion, we have shown here that human eosinophils and neutrophils can metabolize 1-LG and LEA into the novel endogenous lipid mediators 13-HODE-G and 13-HODE-EA, respectively. This is the first study documenting the existence of 13-HODE$\mathrm{G}$ and the ability of human neutrophils and eosinophils to biosynthesize this metabolite and its endogenous analogue, 13-HODE-EA. Deciphering the role of 13-HODE-G and 13-HODE-EA in heath and inflammatory diseases will be of interest, knowing that 15-LO-1 can be dysregulated in inflammation $[46,47]$.

Supplementary Materials: The following are available online at https:/ / www.mdpi.com/article/10 $.3390 /$ cells10092322/s1, Figure S1: Strategy to synthesize 1-LG-d $\mathrm{d}_{5}, 13-\mathrm{HODE}-\mathrm{G}$ and 13-HODE-G-d $\mathrm{d}_{5}$ Figure S2: $1 \mathrm{H}-\mathrm{NMR}$ in CDCl3 of 1-LG-d $\mathrm{d}_{5}$, Figure S3: 13C-NMR in CDCl3 of 1-LG-d $\mathrm{d}_{5}$, Figure S4: 1H-NMR in CDCl3 of 13-HODE-G, Figure S5: 13C-NMR in CDCl3 of 13-HODE-G, Figure S6: HSQC in $\mathrm{CDCl} 3$ of 13-HODE-G, Figure S7: COSY in CDCl3 of 13-HODE-G, Figure S8: 1H-NMR in CDCl3 of 13-HODE-G-d $\mathrm{d}_{5}$, Figure S9: 13C-NMR in CDCl3 of 13-HODE-G-d $\mathrm{d}_{5}$, Figure S10: HSQC in CDCl3 of 13-HODE-G- $\mathrm{d}_{5}$, Figure S11: COSY in $\mathrm{CDCl} 3$ of $13-\mathrm{HODE}-\mathrm{G}-\mathrm{d}_{5}$.

Author Contributions: Conceptualization, A.-S.A., F.T., V.D. and N.F.; Methodology, A.-S.A., F.T., P.L.P., C.M., R.M.V., A.L. and N.F.; Investigation, A.-S.A., F.T., É.D., V.R., M.R., P.-L.P., C.M., M.S., C.S. and R.M.V.; Writing—original draft preparation, A.-S.A., F.T., R.M.V., A.L. and N.F.; Writing—review and editing, A.-S.A., F.T., É.D., V.R., M.K., P.-L.P., C.M., M.S., C.S., R.P., M.L., L.-P.B., R.M.V., A.L., V.D. and N.F.; Visualization, A.-S.A., F.T., É.D., V.R., P.-L.P., R.M.V. and N.F.; Supervision, R.P., M.L., L.-P.B., A.L., V.D. and N.F.; Project administration, A.-S.A., F.T. and N.F.; Funding acquisition, V.D. and N.F. All authors have read and agreed to the published version of the manuscript.

Funding: This work was supported by grants to NF from The Natural Sciences and Engineering Research Council of Canada (RGPIN-2015-04728 and RGPIN-2021-03777) and The Joint International 
Research Unit for chemical and biomolecular research on the microbiome and its impact on metabolic health (UMI-MicroMeNu), which is funded by the Sentinel North Program of Universite Laval. FT was supported by a postdoctoral award from the Joint International Research Unit on Chemical and Biomolecular Studies on the Microbiome and its Impact on Metabolic Health and Nutrition (MicroMeNu). ASA was supported by a PhD award from the Canadian Institutes of Health Research. ED and VR were supported by a Master and a postdoctoral award from the Québec Heart \& Lung Institute Foundation respectively.

Institutional Review Board Statement: The study was conducted according to the guidelines of the Declaration of Helsinki and approved by the Ethics Committee of Centre de recherche de l'Institut Universitaire de Cardiologie et de Pneumologie de Québec.

Informed Consent Statement: Informed consent was obtained from all subjects involved in the study.

Data Availability Statement: The data presented in this study is contained within the article or supplementary material.

Acknowledgments: We would like to thank Hélène Villeneuve, Joanne Milot, and Johane Lepage for providing the blood samples. We also kindly thank Hans-Erik Claesson for providing the 15-LO-1 inhibitor BLX-3887 and Ted Holman for kindly providing human recombinant 15-LO-1 and 15-LO-2. ASA, ED, and NF are members of the Quebec Respiratory Health Research Network.

Conflicts of Interest: The authors declare no conflict of interest. The funders had no role in the design of the study; in the collection, analyses, or interpretation of data; in the writing of the manuscript, or in the decision to publish the results.

\section{References}

1. Turcotte, C.; Chouinard, F.; Lefebvre, J.S.; Flamand, N. Regulation of inflammation by cannabinoids, the endocannabinoids 2-arachidonoyl-glycerol and arachidonoyl-ethanolamide, and their metabolites. J. Leukoc. Biol 2015, 97, 1049-1070. [CrossRef]

2. Di Marzo, V. New approaches and challenges to targeting the endocannabinoid system. Nat. Rev. Drug Discov. 2018, 17, 623-639. [CrossRef]

3. Prescott, S.M.; Majerus, P.W. Characterization of 1,2-diacylglycerol hydrolysis in human platelets. Demonstration of an arachidonoyl-monoacylglycerol intermediate. J. Biol. Chem. 1983, 258, 764-769. [CrossRef]

4. Goparaju, S.K.; Ueda, N.; Taniguchi, K.; Yamamoto, S. Enzymes of porcine brain hydrolyzing 2-arachidonoylglycerol, an endogenous ligand of cannabinoid receptors. Biochem. Pharmacol. 1999, 57, 417-423. [CrossRef]

5. Xie, S.; Borazjani, A.; Hatfield, M.J.; Edwards, C.C.; Potter, P.M.; Ross, M.K. Inactivation of lipid glyceryl ester metabolism in human THP1 monocytes/macrophages by activated organophosphorus insecticides: Role of carboxylesterases 1 and 2. Chem. Res. Toxicol. 2010, 23, 1890-1904. [CrossRef]

6. Wang, R.; Borazjani, A.; Matthews, A.T.; Mangum, L.C.; Edelmann, M.J.; Ross, M.K. Identification of palmitoyl protein thioesterase 1 in human THP1 monocytes and macrophages and characterization of unique biochemical activities for this enzyme. Biochemistry 2013, 52, 7559-7574. [CrossRef]

7. Savinainen, J.R.; Patel, J.Z.; Parkkari, T.; Navia-Paldanius, D.; Marjamaa, J.J.; Laitinen, T.; Nevalainen, T.; Laitinen, J.T. Biochemical and pharmacological characterization of the human lymphocyte antigen B-associated transcript 5 (BAT5/ABHD16A). PLoS ONE 2014, 9, e109869. [CrossRef]

8. Navia-Paldanius, D.; Savinainen, J.R.; Laitinen, J.T. Biochemical and pharmacological characterization of human alpha/betahydrolase domain containing 6 (ABHD6) and 12 (ABHD12). J. Lipid Res. 2012, 53, 2413-2424. [CrossRef] [PubMed]

9. Cravatt, B.F.; Giang, D.K.; Mayfield, S.P.; Boger, D.L.; Lerner, R.A.; Gilula, N.B. Molecular characterization of an enzyme that degrades neuromodulatory fatty-acid amides. Nature 1996, 384, 83-87. [CrossRef] [PubMed]

10. Wei, B.Q.; Mikkelsen, T.S.; McKinney, M.K.; Lander, E.S.; Cravatt, B.F. A second fatty acid amide hydrolase with variable distribution among placental mammals. J. Biol. Chem. 2006, 281, 36569-36578. [CrossRef]

11. Tsuboi, K.; Sun, Y.X.; Okamoto, Y.; Araki, N.; Tonai, T.; Ueda, N. Molecular characterization of N-acylethanolamine-hydrolyzing acid amidase, a novel member of the choloylglycine hydrolase family with structural and functional similarity to acid ceramidase. J. Biol. Chem. 2005, 280, 11082-11092. [CrossRef]

12. Chouinard, F.; Turcotte, C.; Guan, X.; Larose, M.C.; Poirier, S.; Bouchard, L.; Provost, V.; Flamand, L.; Grandvaux, N.; Flamand, N. 2-Arachidonoyl-glycerol- and arachidonic acid-stimulated neutrophils release antimicrobial effectors against E. coli, S. aureus, HSV-1, and RSV. J. Leukoc. Biol. 2013, 93, 267-276. [CrossRef] [PubMed]

13. Chouinard, F.; Lefebvre, J.S.; Navarro, P.; Bouchard, L.; Ferland, C.; Lalancette-Hebert, M.; Marsolais, D.; Laviolette, M.; Flamand, N. The endocannabinoid 2-arachidonoyl-glycerol activates human neutrophils: Critical role of its hydrolysis and de novo leukotriene B4 biosynthesis. J. Immunol. 2011, 186, 3188-3196. [CrossRef] 
14. Larose, M.C.; Turcotte, C.; Chouinard, F.; Ferland, C.; Martin, C.; Provost, V.; Laviolette, M.; Flamand, N. Mechanisms of human eosinophil migration induced by the combination of IL-5 and the endocannabinoid 2-arachidonoyl-glycerol. J. Allergy Clin. Immunol. 2014, 133, 1480-1482. [CrossRef]

15. Kudalkar, S.N.; Kingsley, P.J.; Marnett, L.J. Assay of Endocannabinoid Oxidation by Cyclooxygenase-2. Methods Mol. Biol. 2016, 1412, 205-215. [CrossRef]

16. Watson, J.E.; Kim, J.S.; Das, A. Emerging class of omega-3 fatty acid endocannabinoids \& their derivatives. Prostaglandins Other Lipid Mediat. 2019, 143, 106337. [CrossRef]

17. Moody, J.S.; Kozak, K.R.; Ji, C.; Marnett, L.J. Selective oxygenation of the endocannabinoid 2-arachidonylglycerol by leukocytetype 12-lipoxygenase. Biochemistry 2001, 40, 861-866. [CrossRef]

18. Edgemond, W.S.; Hillard, C.J.; Falck, J.R.; Kearn, C.S.; Campbell, W.B. Human platelets and polymorphonuclear leukocytes synthesize oxygenated derivatives of arachidonylethanolamide (anandamide): Their affinities for cannabinoid receptors and pathways of inactivation. Mol. Pharmacol. 1998, 54, 180-188. [CrossRef]

19. Kozak, K.R.; Gupta, R.A.; Moody, J.S.; Ji, C.; Boeglin, W.E.; DuBois, R.N.; Brash, A.R.; Marnett, L.J. 15-Lipoxygenase metabolism of 2-arachidonylglycerol. Generation of a peroxisome proliferator-activated receptor alpha agonist. J. Biol. Chem. 2002, 277, 23278-23286. [CrossRef] [PubMed]

20. Archambault, A.S.; Turcotte, C.; Martin, C.; Provost, V.; Larose, M.C.; Laprise, C.; Chakir, J.; Bissonnette, E.; Laviolette, M.; Bosse, Y.; et al. Comparison of eight 15-lipoxygenase (LO) inhibitors on the biosynthesis of 15-LO metabolites by human neutrophils and eosinophils. PLoS ONE 2018, 13, e0202424. [CrossRef]

21. Tinto, F.; Archambault, A.S.; Dumais, E.; Rakotoarivelo, V.; Kostrzewa, M.; Martin, C.; Plante, P.L.; Desjardins, Y.; Simard, M.; Pouliot, R.; et al. Synthesis and molecular targets of N-13-hydroxy-octadienoyl-ethanolamine, a novel endogenous bioactive 15-lipoxygenase-derived metabolite of N-linoleoyl-ethanolamine found in the skin and saliva. Biochim. Biophys. Acta Mol. Cell Biol. Lipids 2021, 1866, 158954. [CrossRef] [PubMed]

22. Yang, R.; Fredman, G.; Krishnamoorthy, S.; Agrawal, N.; Irimia, D.; Piomelli, D.; Serhan, C.N. Decoding functional metabolomics with docosahexaenoyl ethanolamide (DHEA) identifies novel bioactive signals. J. Biol. Chem. 2011, 286, 31532-31541. [CrossRef]

23. Engels, F.; Kessels, G.C.; Henricks, P.A.; Nijkamp, F.P. Preferential formation of 13-hydroxylinoleic acid by human peripheral blood eosinophils. Prostaglandins 1996, 52, 117-124. [CrossRef]

24. Soberman, R.J.; Harper, T.W.; Betteridge, D.; Lewis, R.A.; Austen, K.F. Characterization and separation of the arachidonic acid 5-lipoxygenase and linoleic acid omega-6 lipoxygenase (arachidonic acid 15-lipoxygenase) of human polymorphonuclear leukocytes. J. Biol. Chem. 1985, 260, 4508-4515. [CrossRef]

25. Kavadia, M.R.; Yadav, M.G.; Odaneth, A.A.; Lali, A.M. Production of glyceryl monostearate by immobilized candida antarctica B lipase in organic media. J. Appl. Biotechnol. Bioeng. 2017, 2, 7. [CrossRef]

26. van der Stelt, M.; Nieuwenhuizen, W.F.; Veldink, G.A.; Vliegenthart, J.F. Dioxygenation of N-linoleoyl amides by soybean lipoxygenase-1. FEBS Lett. 1997, 411, 287-290. [CrossRef]

27. Turcotte, C.; Archambault, A.S.; Dumais, E.; Martin, C.; Blanchet, M.R.; Bissonnette, E.; Ohashi, N.; Yamamoto, K.; Itoh, T.; Laviolette, M.; et al. Endocannabinoid hydrolysis inhibition unmasks that unsaturated fatty acids induce a robust biosynthesis of 2-arachidonoyl-glycerol and its congeners in human myeloid leukocytes. FASEB J. 2020, 34, 4253-4265. [CrossRef]

28. Archambault, A.S.; Poirier, S.; Lefebvre, J.S.; Robichaud, P.P.; Larose, M.C.; Turcotte, C.; Martin, C.; Provost, V.; Boudreau, L.H.; McDonald, P.P.; et al. 20-Hydroxy- and 20-carboxy-leukotriene (LT) B4 downregulate LTB4 -mediated responses of human neutrophils and eosinophils. J. Leukoc. Biol. 2019, 105, 1131-1142. [CrossRef] [PubMed]

29. Flamand, N.; Boudreault, S.; Picard, S.; Austin, M.; Surette, M.E.; Plante, H.; Krump, E.; Vallee, M.J.; Gilbert, C.; Naccache, P.; et al. Adenosine, a potent natural suppressor of arachidonic acid release and leukotriene biosynthesis in human neutrophils. Am. J. Respir. Crit. Care Med. 2000, 161, S88-S94. [CrossRef]

30. Schmidt, M.W.; Baldridge, K.K.; Boatz, J.A.; Elbert, S.T.; Gordon, M.S.; Jensen, J.H.; Koseki, S.; Matsunaga, N.; Nguyen, K.A.; Su, S.; et al. General atomic and molecular electronic structure system. J. Comput. Chem. 1993, 14, 16.

31. Fox, T.; Kollman, P.K. Application of the RESP Methodology in the Parametrization of Organic Solvents. J. Phys. Chem. 1998, 102, 9. [CrossRef]

32. Morris, G.M.; Huey, R.; Lindstrom, W.; Sanner, M.F.; Belew, R.K.; Goodsell, D.S.; Olson, A.J. AutoDock4 and AutoDockTools4: Automated docking with selective receptor flexibility. J. Comput. Chem. 2009, 30, 2785-2791. [CrossRef] [PubMed]

33. Iannotti, F.A.; De Maio, F.; Panza, E.; Appendino, G.; Taglialatela-Scafati, O.; De Petrocellis, L.; Amodeo, P.; Vitale, R.M. Identification and characterization of cannabimovone, a cannabinoid from cannabis sativa, as a novel ppargamma agonist via a combined computational and functional study. Molecules 2020, 25, 1119. [CrossRef]

34. Case, D.A.; Aktulga, H.M.; Belfon, K.; Ben-Shalom, I.Y.; Brozellm, S.R.; Cerutti, D.S.; Cheatham, T.E.; Cisneros, G.A.; Cruzeiro, V.W.D.; Darden, T.A.; et al. AMBER 2016; University of California: San Francisco, CA, USA, 2016.

35. Zoerner, A.A.; Gutzki, F.M.; Batkai, S.; May, M.; Rakers, C.; Engeli, S.; Jordan, J.; Tsikas, D. Quantification of endocannabinoids in biological systems by chromatography and mass spectrometry: A comprehensive review from an analytical and biological perspective. Biochim. Biophys. Acta 2011, 1811, 706-723. [CrossRef]

36. Turcotte, C.; Dumais, E.; Archambault, A.S.; Martin, C.; Blanchet, M.R.; Bissonnette, E.; Boulet, L.P.; Laviolette, M.; Di Marzo, V.; Flamand, N. Human leukocytes differentially express endocannabinoid-glycerol lipases and hydrolyze 2-arachidonoyl-glycerol and its metabolites from the 15-lipoxygenase and cyclooxygenase pathways. J. Leukoc. Biol. 2019, 106, 1337-1347. [CrossRef] 
37. Deutsch, D.G.; Omeir, R.; Arreaza, G.; Salehani, D.; Prestwich, G.D.; Huang, Z.; Howlett, A. Methyl arachidonyl fluorophosphonate: A potent irreversible inhibitor of anandamide amidase. Biochem. Pharmacol. 1997, 53, 255-260. [CrossRef]

38. Han, H.; Liang, X.; Ekberg, M.; Kritikou, J.S.; Brunnstrom, A.; Pelcman, B.; Matl, M.; Miao, X.; Andersson, M.; Yuan, X.; et al. Human 15-lipoxygenase-1 is a regulator of dendritic-cell spreading and podosome formation. FASEB J. 2017, 31, 491-504. [CrossRef]

39. Whitman, S.; Gezginci, M.; Timmermann, B.N.; Holman, T.R. Structure-activity relationship studies of nordihydroguaiaretic acid inhibitors toward soybean, 12-human, and 15-human lipoxygenase. J. Med. Chem 2002, 45, 2659-2661. [CrossRef]

40. Tan, C.M.; Chen, G.S.; Chen, C.S.; Chang, P.T.; Chern, J.W. Design, synthesis and biological evaluation of benzo[1.3.2]dithiazolium ylide 1,1-dioxide derivatives as potential dual cyclooxygenase-2/5-lipoxygenase inhibitors. Bioorg. Med. Chem. 2011, 19, 6316-6328. [CrossRef]

41. Suriano, F.; Manca, C.; Flamand, N.; Depommier, C.; Van Hul, M.; Delzenne, N.M.; Silvestri, C.; Cani, P.D.; Di Marzo, V. Exploring the endocannabinoidome in genetically obese $(o b / o b)$ and diabetic $(d b / d b)$ mice: links with inflammation and gut microbiota. Biochim. Biophys. Acta Mol. Cell Biol Lipids 2021. under review.

42. Urquhart, P.; Nicolaou, A.; Woodward, D.F. Endocannabinoids and their oxygenation by cyclo-oxygenases, lipoxygenases and other oxygenases. Biochim. Biophys. Acta 2015, 1851, 366-376. [CrossRef]

43. Ivanov, I.; Kakularam, K.R.; Shmendel, E.V.; Rothe, M.; Aparoy, P.; Heydeck, D.; Kuhn, H. Oxygenation of endocannabinoids by mammalian lipoxygenase isoforms. Biochim. Biophys. Acta Mol. Cell Biol Lipids 2021, 1866, 158918. [CrossRef] [PubMed]

44. Upston, J.M.; Neuzil, J.; Witting, P.K.; Alleva, R.; Stocker, R. Oxidation of free fatty acids in low density lipoprotein by 15lipoxygenase stimulates nonenzymic, alpha-tocopherol-mediated peroxidation of cholesteryl esters. J. Biol. Chem. 1997, 272, 30067-30074. [CrossRef] [PubMed]

45. Kammerer, I.; Ringseis, R.; Biemann, R.; Wen, G.; Eder, K. 13-hydroxy linoleic acid increases expression of the cholesterol transporters ABCA1, ABCG1 and SR-BI and stimulates apoA-I-dependent cholesterol efflux in RAW264.7 macrophages. Lipids Health Dis. 2011, 10, 222. [CrossRef]

46. Chu, H.W.; Balzar, S.; Westcott, J.Y.; Trudeau, J.B.; Sun, Y.; Conrad, D.J.; Wenzel, S.E. Expression and activation of 15-lipoxygenase pathway in severe asthma: Relationship to eosinophilic phenotype and collagen deposition. Clin. Exp. Allergy 2002, 32, 1558-1565. [CrossRef]

47. Singh, N.K.; Rao, G.N. Emerging role of 12/15-Lipoxygenase (ALOX15) in human pathologies. Prog. Lipid Res. $2019,73,28-45$. [CrossRef] [PubMed] 